NBER WORKING PAPER SERIES

\title{
EARNINGS DYNAMICS AND INEQUALITY \\ AMONG CANADIAN MEN, 1976-1992: \\ EVIDENCE FROM LONGITUDINAL INCOME TAX RECORDS
}

\author{
Michael Baker \\ Gary Solon \\ Working Paper 7370 \\ http://www.nber.org/papers/w7370 \\ NATIONAL BUREAU OF ECONOMIC RESEARCH \\ 1050 Massachusetts Avenue \\ Cambridge, MA 02138 \\ September 1999
}

We are grateful for many discussions with Rene Morissette and for comments from Robert Barsky, John Bound, Julie Berry Cullen, Steven Haider, Aloysius Siow, and seminar participants at Toronto, Michigan, ANU, Berkeley, California at San Diego, CIRANO, INSEE, Melbourne, NBER, New South Wales, Ohio State, Sydney, and Western Ontario. The research support of Statistics Canada and SSHRC (Baker, grant no. 410-96-0187) are gratefully acknowledged. Any opinions expressed are those of the authors, and not of the National Bureau of Economic Research or of Statistics Canada.

(C) 1999 by Michael Baker and Gary Solon. All rights reserved. Short sections of text, not to exceed two 
paragraphs, may be quoted without explicit permission provided that full credit, including (C) notice, is given to the source.

Earnings Dynamics and Inequality among

Canadian Men, 1976-1992: Evidence from

Longitudinal Income Tax Records

Michael Baker and Gary Solon

NBER Working Paper No. 7370

September 1999

JEL No. F2, H73, Q2

\section{$\underline{\text { ABSTRACT }}$}

Several recent studies have found that earnings inequality in Canada has grown considerably since the late 1970's. Using an extraordinary data base drawn from longitudinal income tax records, we decompose this growth in earnings inequality into its persistent and transitory components. We find that the growth in earnings inequality reflects both an increase in long-run inequality and an increase in earnings instability. The large size of our earnings panel allows us to estimate and test richer models of earnings dynamics than could be supported by the relatively small panel surveys used in U.S. research. The Canadian data strongly reject several restrictions commonly imposed in the U.S. literature, and they also suggest that imposing these evidently false restrictions may lead to distorted inferences about earnings dynamics and inequality trends.

Michael Baker

Department of Economics

University of Toronto

150 St. George St.

Toronto, ON M5S 3G7

and NBER

baker@chass.utoronto.ca
Gary Solon

Department of Economics

University of Michigan

611 S. Tappan St.

Ann Arbor, MI 48109-1220

gsolon@umich.edu 


\section{Earnings Dynamics and Inequality among Canadian Men, 1976-1992:}

\section{Evidence from Longitudinal Income Tax Records}

\section{Introduction}

Scores of studies have documented the growth of earnings inequality in developed Western economies since the late 1970's. Although a large proportion of this literature has focused on the United States, ${ }^{1}$ numerous studies have examined changes in Canada's earnings distribution. ${ }^{2}$ The Canadian studies do not agree in every detail, but by and large they indicate that earnings inequality has increased substantially, though perhaps not quite as dramatically as in the United States. They also find that the return to education in Canada, unlike the return in the United States, has increased little if at all. That is, the increase in Canadian earnings inequality has occurred mainly within education groups, rather than between them. Another contrast with the United States is that a larger share of Canada's growth in annual earnings inequality has arisen from increased dispersion in annual work hours rather than in hourly wage rates.

A few recent U.S. studies (Gottschalk and Moffitt, 1994; Moffitt and Gottschalk, 1995; Buchinsky and Hunt, 1996; Gittleman and Joyce, 1996; Haider, 1998) have stressed the importance of decomposing the growth in earnings inequality into persistent and transitory components. On one hand, if the increase in earnings inequality has been driven mainly by a rise in returns to education and other persistent worker attributes, then the observed increase in crosssectional inequality signifies increased inequality in long-run earnings. In this scenario, the

\footnotetext{
${ }^{1}$ See, for example, Bound and Johnson (1992), Katz and Murphy (1992), Juhn, Murphy, and Pierce (1993), and the survey article by Katz and Autor (forthcoming).

${ }^{2}$ See, for example, Bar-Or, Burbridge, Magee, and Robb (1995), Beach, Slotsve, and Vaillancourt (1996), Beaudry and Green (1997), Blackburn and Bloom (1993), Davis (1992), DiNardo and Lemieux (1997), Freeman and Needels (1993), Gottschalk (1993), Morissette and Berube (1996), Picot (1996), and Richardson (1997).
} 
chronically rich have gotten richer and the chronically poor poorer. On the other hand, if the increase in cross-sectional inequality has been driven mainly by a rise in the transitory component of earnings variation, then long-run inequality may have increased very little. In this scenario, the chronically rich have not gotten richer in the long run, and the chronically poor have not gotten poorer, but there has been an increase in year-to-year "churning" through the ranks of the annual earnings distribution. ${ }^{3}$ As it turns out, the message of the U.S. studies is that both components of earnings inequality have increased. In Haider's words, "annual inequality increased because of fairly equal increases of a persistent component and an instability component."4

In this paper we make two contributions to the literature on earnings dynamics and inequality trends. First, using almost two decades of longitudinal earnings information drawn from income tax records, we decompose Canada's growth in earnings inequality into persistent and transitory components. To what extent does Canada's increasing inequality reflect greater year-to-year earnings fluctuation, and to what extent does it arise from an increased dispersion in permanent earnings? Given the integration of the U.S. and Canadian economies, one might expect to find the same answer as in the U.S. literature. The rise in long-run inequality in the United States, however, has been tied to a large increase in the return to education, which has not taken place in Canada. The Canadian experience need not be the same as the U.S. experience, and any similarities and differences can be instructive about labor market developments in both countries (as well as in other parts of the world).

\footnotetext{
${ }^{3}$ As noted by Haider, however, even purely transitory increases in earnings dispersion can have welfare costs. For example, transitory earnings declines can force consumption reductions for liquidity-constrained individuals even if their permanent earnings are unaffected.

${ }^{4}$ Another indication that persistent inequality has grown is the increased dispersion in consumption expenditures. See Cutler and Katz (1992) and Attanasio and Davis (1996). Blundell and Preston (1998) present related evidence for the United Kingdom.
} 
Second, we exploit our extraordinary data set to achieve some methodological advances. The relatively small scale of the available U.S. panel surveys has forced U.S. researchers to rely on simple models that impose economically implausible restrictions. Thanks to the much larger sample size of our data set, we are able to estimate much richer models that nest the various specifications used in the U.S. literature. We therefore are able to test the restrictions commonly used in U.S. research, and we also can explore the sensitivity of substantive results to the imposition of those restrictions. Our data strongly reject some of those restrictions, and they also indicate that the imposition of those evidently false restrictions can distort substantive inferences about the nature of earnings dynamics and the sources of changes in earnings inequality.

In the next section, we provide a detailed description of our data base. In Section III, we develop econometric models of earnings dynamics and discuss our estimation methods. Section IV contains our empirical results, and Section V summarizes and discusses the main findings.

\section{II .Data}

\section{A. Data Base}

The data base we use was developed by Statistics Canada from the T-4 Supplementary Tax File maintained by Revenue Canada. ${ }^{5}$ This file is a one-percent random sample of all individuals who received a $\mathrm{T}-4$ supplementary tax form, and filed a tax return (a $\mathrm{T}-1$ form), in at least one year between 1975 and 1993. T-4's are issued by employers for any earnings that (1) exceed a certain annual threshold and/or (2) trigger income tax, contributions to Canada's public pension plans, or unemployment insurance premiums. ${ }^{6} \mathrm{~T}-4$ 's are analogous to the W-2

\footnotetext{
${ }^{5}$ The construction of the data base is described in Morissette and Berube (1996). Our description draws heavily on this source.
} 
forms issued by employers in the United States, and the T-1 forms are the counterparts of the ever-popular 1040 forms. The annual threshold (condition 1) was equal to $\$ 250$ for the years 1975-1988 and $\$ 500$ for 1989 - 1993 . This provision likely superseded the requirements of condition 2 in the vast majority of cases in which T-4's were issued over the sample period. ${ }^{7}$ To obtain a sample which is consistent over time, we exclude all forms with annual earnings less than $\$ 250$ in 1975 dollars. The resulting threshold equals, for example, $\$ 645$ in 1989 and $\$ 738$ in 1993. Therefore, annual earnings is the sum of earnings from all jobs held by an individual in a given year that paid at least $\$ 250$ in 1975 constant dollars.

This measure of earnings has several advantages over its counterparts in survey data and other administrative files. Most importantly, it is based on employers' reports under the provisions of the income tax laws. Therefore, the earnings variable should be free of the measurement error often observed in survey data due to, for example, recall error, rounding error, and top-coding. Also, missing values should be of limited concern to the extent that tax compliance is widespread, or that evasion is more typically an individual (rather than employer) infraction and/or involves other types of income. Note that, unlike other tax-file-based data, the earnings measure is not obtained from tax returns (the T-1 form). This is important as the decision to file a return is not exogenous, and the incentives for doing so may change over time,

\footnotetext{
${ }^{6}$ The data include incorporated self-employed individuals who pay themselves a salary, but not other self-employed workers. The self-employed presumably have more volatile earnings than most workers, and their share of the Canadian work force has trended slightly upwards over our sample period. Our finding below that earnings instability has increased in Canada is all the more striking in light of our failure to encompass all of the selfemployed.

${ }^{7}$ Income tax is deducted whenever an employee's annual income (earnings plus interest income, dividends, etc.) exceeds his or her personal exemption. In most cases, the underlying annual earnings should be higher than the current year's threshold. Public pension plan contributions are owed on earnings which exceed the year's basic exemption, which ranged from $\$ 700$ in 1975 up to $\$ 3500$ in 1993 . Finally, unemployment insurance contributions are made whenever employment exceeds certain time (15 hours per week in 1993) or earnings ( $\$ 149$ per week in 1993) thresholds. It is possible that an individual could be issued a T-4 form for weekly work that triggered
} 
which could introduce selection effects to the data. ${ }^{8}$ In the T-4 file, the only information taken from $\mathrm{T}-1$ forms is the birth date and sex of the individual. To obtain this information, it is necessary that he or she filed a tax return at least once in the sample period. While it would be preferable to have data that are completely independent of an individual's decision to file a return, this is a much weaker requirement than consecutive filing over the sample period.

One limitation of the T-4 file is that, like most administrative data, it contains little demographic information on individuals. For example, we do not know the educational attainment of our sample members and therefore are unable to decompose earnings inequality into the portions occurring within and between education categories. Instead, like most U.S. studies that decompose the rise in earnings inequality into persistent and transitory components, we consider changing returns to education as merely one aspect of change in persistent inequality. Given the evidence that returns to education have not changed much in Canada, our inability to isolate earnings differences between education categories is less important than it would be in the U.S. context.

The target group in our sample selection is males between the ages of 25 and 58 . These individuals will likely have already completed most of their schooling, and are too young to be strongly affected by the trend to earlier retirement. ${ }^{9}$ In constructing our analysis sample, we refine Haider's (1998) revolving balanced panel design to take advantage of the very large size of

unemployment insurance contributions even though annual earnings do not exceed the annual threshold ( $\$ 250$ or $\$ 500$ ). We expect that these cases are of limited importance.

${ }^{8}$ Of particular concern in the present context is the introduction during the late 1980's of the Goods and Services Tax, which included a new refundable tax credit for low-income Canadians. In a study based on tax returns, such as Beach and Finnie (1997), the resulting change in the population of return-filers could be confounded with changes in the earnings distribution.

${ }^{9}$ There has been a strong increase in school enrollment among individuals 17-24 over this period (Morissette, 1997), which might affect our inference if we included younger males. Application for a public pension in Canada can be made as early as age 60 . 
the T-4 file. We begin by identifying the nineteen two-year birth cohorts who are between the ages 24 and 59 for at least nine years in the period 1975 through 1993, and select all males who had positive earnings in each year that the age requirement is met. ${ }^{10}$ We then discard the first and last years of earnings for each individual. This is done to ensure that a consistent selection criterion is applied to each year of positive earnings; that is, we only include years of positive earnings which are bordered by years of positive earnings. The concern is that, without this requirement, the earnings variances in the first and last years will be inflated by labor market entry, retirement, or migration in or out of Canada. The end result is a balanced earnings panel for each cohort, with the panel length varying across cohorts. Our overall analysis sample contains 32,105 individuals, and the sample size for each cohort rivals the pooled sample sizes available in common longitudinal data sets. Table 1 contains a summary of the cohorts/panels that are included through this process.

A fully balanced panel design is not appropriate for the current purpose because average age and time will be perfectly collinear, and it will be difficult to separate the effects of age and time on earnings inequality. Our inference is based on an aggregate panel in which the (balanced) cohort panels are stacked. As is evident in the second column of Table 2, the age range in this larger sample remains approximately constant over much of the sample period, thus breaking the direct link between time and age, though the sample does age somewhat between 1976 and 1981 and again between 1987 and 1992.

\footnotetext{
${ }^{10}$ By requiring consecutive years of positive earnings, we lose individuals who have particularly long spells of joblessness. Note, however, that individuals in our sample can have jobless spells up to 22 months long, depending on how they fall across the calendar year. Also, because individuals are identified in the T-4 file by their Social Insurance Number (SIN), we will lose track of a person if he changes his SIN in the sample period. This might lead us to mistakenly infer that an individual leaves when this change takes place.
} 
An alternative approach would be to use an unbalanced sample design in which any years of positive earnings for individuals satisfying the age requirements in the sample period would be included. The obvious advantage here is that the resulting panel is more representative of individuals with positive earnings at a point in time. In practice, however, unbalanced panels can pose difficult estimation problems for the types of models used here. ${ }^{11}$ In addition, the various sample moments for a given cohort are based on somewhat different samples, so that measured changes over time may confound sample composition effects with true time and life-cycle effects. ${ }^{12}$ Our approach avoids those problems and still allows the separation of time and age effects. Its most obvious shortcomings are the possible selection effects of focusing on individuals with at least nine consecutive years of positive earnings, and that earnings covariances of different orders are observable for different numbers of cohorts who, in turn, face different selection criteria. For example, sixteenth-order covariances are observed only for the nine cohorts born in 1934/35 through 1950/51. The individuals in these cohorts have nineteen consecutive years of positive earnings. In contrast, first-order covariances are observed for all cohorts, which include individuals who have as few as nine consecutive years of positive earnings. Some direct evidence of how the aggregate balanced panel represents the target population of males aged 25 to 58 is provided in the next subsection.

\footnotetext{
${ }^{11}$ Moffitt and Gottschalk (1995) provide evidence of the sorts of problems encountered with unbalanced panels in this context.

${ }^{12}$ An obvious example is that the variances for years $t$ and $s$ would be based on different samples. A more subtle example is that the variance in year $t$ would be estimated on the basis of all individuals with positive earnings in that year, but the estimated autocovariance between years $t$ and $s$ would be based on only those positive earners in year $t$ who also had positive earnings in year $s$.
} 


\section{B. Overview of Trends in Inequality}

In the third and fourth columns of Table 2, we present the sample size and variance of $\log$ earnings for all the individuals in our pooled analysis sample. For example, in 1976 this includes the selected individuals in cohorts born in 1924/25 through 1950/51. The variance shows a clear upward trend over our sample period, and it displays substantial cyclical movements as well. To recognize the latter, it helps to know that the Canadian labor market was fairly stable from 1976 through 1981, with annual unemployment rates ranging between 7.2 percent and 8.4 percent. Unlike the United States, Canada did not experience a recession in 1980. It was hard hit by the 1982 recession, however, with unemployment rising to 11.0 percent in 1982 and 11.9 percent in 1983. Unemployment gradually receded afterwards, but leaped again to 10.4 percent in 1991 and 11.3 percent in 1992 .

The variance series in the fourth column is plotted as the solid line in Figure 1. The variance rises by more than a third in the 1982 recession and then falls gradually in the expansion of the late 1980's, although it never reaches its pre-recession levels. In the recession of the early 1990 's, the variance rises again, this time to a new high. This time-series behavior of earnings dispersion in our data set is altogether consistent with the patterns reported by the Canadian studies cited in footnote 2. Most of those studies are based on Canada's Survey of Consumer Finances (SCF), and it is reassuring that the SCF data and our data based on tax reports tell the same story. The advantage of our data set is that, because of its longitudinal aspect, we will be able to sort the trend toward greater earnings inequality into its persistent and transitory components.

In the remaining columns of Table 2 , we provide some evidence of how the trends in our revolving balanced panel represent the experience of our target population. In the fifth and sixth 
columns, we present the sample sizes and variances of log earnings when we maintain the same age ranges as in our analysis sample but include all individuals with positive earnings in a given year. In many years, the sample size almost doubles, as do the variances. Next, in the seventh and eighth columns, we examine the sample of individuals aged 25 to 58 who had positive earnings in a given year. In this step we focus on a constant age interval, so the sample does not age over time. While there are some minor discrepancies from the previous two columns, it is clear that the requirement of positive earnings in consecutive years, rather than marginal aging over time, accounts for the differences in the variances between our analysis sample and the sample of all males aged 25 to 58 .

Our revolving balanced sample approach leads to smaller estimates of the variance of log earnings, but they appear to be smaller than the variances in the other samples by a roughly fixed factor of one-half. This suggests that the variances in the alternative samples may follow similar patterns over time. This is important since our primary focus is on changes in earnings inequality over time, rather than its absolute level. In Figure 1, we also graph the time pattern of variances in our two comparison samples. As expected, they appear to shadow the variances in our analysis sample. In fact, the correlation coefficient between the variances in our analysis sample and the sample with the same age restrictions but all individuals with positive earnings is 0.957 . Likewise, the correlation coefficient between the variances in the analysis sample and the sample of individuals $25-58$ with positive earnings is $0.943 .{ }^{13}$ The primary discrepancy appears on a cyclical basis, with the variance in the analysis sample growing relative to the variance in the larger samples during recessions. This pattern is unsurprising because lower earners

\footnotetext{
${ }^{13}$ Furthermore, there is similar coherence in other moments. The correlation coefficients between mean log earnings in the analysis sample and the other two samples are 0.999 and 0.997 respectively.
} 
presumably are especially prone to drop out of the unbalanced larger samples during recessions. ${ }^{14}$ This sample composition effect dampens the countercyclicality of earnings dispersion in the unbalanced samples. In the analysis sample, which reduces the sample composition effect by following the same workers over time, the true countercyclicality of earnings dispersion is more apparent. $^{15}$

Overall, although the level of earnings dispersion is much lower in the analysis sample, all three samples show similar behavior over time. Where they differ the most, in their cyclical amplitudes, the analysis sample probably provides a more accurate picture. At the least, it should provide a useful depiction of earnings inequality among those men with relatively stable employment careers.

In Figures 2 and 3, we present some detail on how different age groups within our analysis sample fared over the period. In Figure 2, we plot mean log earnings for five-year age categories, normalizing each series to equal 1 in 1979 to provide a common basis of comparison across the series of different lengths. For example, as documented in the second column of Table 2, the complete age group 26-30 is visible in the analysis sample only between 1976 and 1987, while the age group 51-55 is visible only from 1979 to 1992. Mean log earnings for the different groups moves in tandem up until 1982, but then we observe divergence. For example, by 1987 (the last year for the 26-to-30-year-olds) the difference in average log earnings between 46-to-50-yearolds and 26-to-30-year-olds has increased roughly 2.1 percent over its level in 1979. Further

\footnotetext{
${ }^{14}$ For a discussion of U.S. evidence on the greater employment cyclicality of low earners, see Solon, Barsky, and Parker (1994).

${ }^{15}$ The U.S. evidence discussed in Solon, Barsky, and Parker (1994) suggests that the countercyclicality of dispersion in annual earnings arises mainly from countercyclicality in the dispersion of annual hours, rather than in the dispersion of hourly wage rates. We are not aware of Canadian evidence on this point.
} 
changes are observed in the late 1980's and early 1990's. The difference in log earnings between 31-to-35-year-olds and 46-to-50-year-olds is up 1.2 percent in 1987 and 2.6 percent by 1992.

In Figure 3, we provide complementary information about the variance of log earnings. Again we normalize each series to equal 1 in 1979. Corresponding to the effects of the recession on the means, there is a sharp increase in the variances in 1982 which is particularly severe for younger workers. In 1983, the variance for 26-to-30-year- olds is up 80 percent over its level in 1979, while the increase for older workers is on the order of 25 to 30 percent. The recession of the early 1990's also has the greatest effect on the young. Between 1989 and 1992, the increases in the variances for 31-to-35-year-olds and 36-to-40-year-olds are 68 percent and 42 percent respectively. In contrast, the increase over the same period is 29 percent for 41-to-45-year-olds, 37 percent for 46-to-50-year-olds, and 4 percent for 50-to-55-year-olds.

One previous study, by Morissette and Berube (1996), has used the same tax data we use to generate preliminary evidence on the extent to which the growth in annual earnings inequality reflects an increase in persistent inequality. To get a measure of persistent inequality, Morissette and Berube take a sample of workers within each of a variety of age ranges as of 1975 , they sum the workers' earnings over the 1975-1984 period, and then they calculate several dispersion measures for the ten-year earnings total. ${ }^{16}$ Then they perform the same exercise for the 19841993 earnings total and compare the dispersion measures between the two ten-year periods. For example, for men ages 35-44 as of 1975, the coefficient of variation in the 1975-1984 total of earnings is 0.512 . For men $35-44$ as of 1984 , the coefficient of variation in the $1984-1993$

\footnotetext{
${ }^{16}$ Surprisingly, Morissette and Berube base their tabulated results on total nominal earnings with no discounting. They report in a footnote, however, that they obtain qualitatively similar results for real earnings discounted annually by 3 or 7 percent.
} 
earnings total is 12 percent higher at 0.573 . Regardless of age range or dispersion measure, Morissette and Berube find greater dispersion in the later period.

Morissette and Berube's evidence strongly suggests that the persistent component of earnings variation did increase between 1975-1984 and 1984-1993, but this finding leaves some important questions unanswered. First, a comparison of two ten-year periods does not pinpoint the timing of the increase in persistent earnings inequality, and this creates some ambiguity in how to interpret the comparison. For example, to what extent does the difference between periods reflect a secular trend or a difference in business cycle conditions? As Morissette and Berube acknowledge, "Since the unemployment rates observed since the mid-eighties were higher than those of the mid-seventies, one possibility is that the increase in long-term inequality that we found simply reflects a cyclical effect. Because we have been comparing two periods and thus have been using only two observations, we have been unable to control for such an effect." Second, their evidence does not provide a direct indication of whether (or when) the transitory component of earnings variation also increased. The remainder of our paper develops and estimates models designed to answer these questions.

\section{Econometric Models and Estimation Methods}

\section{A. Models}

Earnings dynamics and their implications for the connection between current and lifetime income have long been of central concern in numerous areas of economic research. Research on the distinction between the inequality observed in annual cross-sections of earnings and inequality in long-run earnings is just one such area. Another classic example is the research, going back at least to Friedman (1957), on the difference in the response of consumption to changes in 
transitory versus permanent income. Still another example is the recent research showing that the intergenerational correlation in earnings appears far greater for long-run measures of earnings than it does for single-year measures (Solon, forthcoming).

Because of its recurring importance in many research areas, earnings mobility has been the subject of a voluminous empirical literature. ${ }^{17}$ To explain the connection between the models in the literature and the models estimated in this paper, we will begin with a rudimentary version of the canonical variance-components models of earnings dynamics and then embellish it in order to allow for changes over time in both the persistent and transitory components of earnings variation.

Let $Y_{i b t}$ denote the log earnings in year $t$ of the $i^{\text {th }}$ sample member born in year $b$. Then

$$
Y_{i b t}=\mu_{b t}+y_{i b t}
$$

expresses $Y_{i b t}$ as the cohort-specific mean $\mu_{b t}$ in year $t$ plus an individual-specific deviation $y_{i b t}$ from that mean. Most previous studies of earnings dynamics have attempted to partial out $\mu_{b r}$ with preliminary regression adjustments for year and age (or experience) effects and then have estimated models for the dynamics of $y_{i b t}$. By doing so, they have characterized both the crosssectional variance and the year-to-year mobility in relative earnings within a cohort.

A stripped-down version of the commonly used models for $y_{i b t}$ is

$$
y_{i b t}=\alpha_{i b}+v_{i b t}
$$

\footnotetext{
${ }^{17}$ See Atkinson, Bourguignon, and Morrisson (1992) for an elegant survey of the literature up through most of the 1980's. See Baker (1997) and Haider (1998) for more recent analyses and for references to other studies since the late 1980's. Aside from the study by Beach and Finnie (1997) cited in footnote 8, the only other study of Canadian earnings dynamics of which we are aware is Kennedy (1989), which uses a small sample of earnings histories drawn from a Canada Pension Plan administrative file. Kennedy does not explore how the transitory and persistent components of earnings variation have changed over time.
} 
where the permanent earnings component $\alpha_{i b}$ has population variance $\sigma_{\alpha}^{2}$, the transitory component $v_{i b t}$ has variance $\sigma_{v}^{2}$ and is serially uncorrelated, and $\alpha_{i b}$ and $v_{i b t}$ are orthogonal to each other. A nice feature of this exceedingly simple model is that it provides a clear representation of the distinction between inequality in current and permanent earnings. The variance in current relative earnings $y_{i b t}$ is

$$
\operatorname{Var}\left(y_{i b t}\right)=\sigma_{\alpha}^{2}+\sigma_{v}^{2} \text {, }
$$

which exceeds $\sigma_{\alpha}^{2}$, the variance in the permanent component of earnings, by $\sigma_{v}^{2}$, the variance of transitory earnings. ${ }^{18}$

This rudimentary model, however, possesses several weaknesses that render it inappropriate for our purposes. To begin with, it does not allow for changes in earnings inequality over time. Following Katz (1994), Moffitt and Gottschalk (1995), and Haider (1998), a simple way to incorporate such changes is with the enhanced model

$$
y_{i b t}=p_{t} \alpha_{i b}+\lambda_{t} v_{i b t}
$$

where $p_{t}$ and $\lambda_{t}$ are the respective year-specific factor loadings on the permanent and transitory components of relative earnings. Then the variance of $y_{i b t}$ becomes

$$
\operatorname{Var}\left(y_{i b t}\right)=p_{t}^{2} \sigma_{\alpha}^{2}+\lambda_{t}^{2} \sigma_{v}^{2}
$$

As this expression shows, an increase in either factor loading generates increased dispersion in current earnings. The character of the change in inequality, however, depends critically on which factor changes. A rise in $p_{t}$ increases inequality in long-run earnings as well as in current earnings. The relative advantage of workers with chronically high earnings increases, as does the

\footnotetext{
${ }^{18}$ The predominant role of $\sigma_{\alpha}^{2}$ in long-run earnings inequality is demonstrated for a more general model in Solon (1999).
} 
relative disadvantage of those with chronically low earnings. On the other hand, if $\lambda_{t}$ increases without any change in $p_{t}$, inequality in current earnings rises because of an increase in year-toyear volatility, but there is no increase in the variance of the permanent component of earnings.

Since an increase in either factor loading increases the variance of $y_{i b t}$, variances by themselves cannot identify which component of inequality has changed. What does identify the source of the increased cross-sectional inequality is changes in observed autocovariances. In an era when $p_{t}$ rises to a higher level, the autocovariances grow along with the variances. Indeed, if $p_{t}$ increases without a change in $\lambda_{t}$, the autocovariances grow in greater proportion than the variances, so the autocorrelations increase. In other words, the increase in cross-sectional inequality is accompanied by a decrease in mobility. In contrast, if $\lambda_{t}$ increases without a change in $p_{t}$, the rise in variances is not accompanied by a rise in autocovariances, and the autocorrelations decline. Although this point is particularly clear in the context of the model in equation (4), it does extend to more complex models. Heuristically, an increase in $p_{t}$ preserves the order of individuals in the earnings distribution, but spreads them out further, and this greater spread persists from year to year. An increase in $\lambda_{t}$ leads to more scrambling of individuals' order in the annual earnings distribution, and the scrambling gets redone every year.

Although the model in equation (4) does incorporate changes in both the persistent and transitory components of earnings inequality, it still overlooks several important features of earnings dynamics that have been documented in the previous literature. First, several studies have found evidence of persistent heterogeneity across individuals not only in their levels of 
earnings, but in their growth rates. ${ }^{19}$ Second, some earnings shocks have permanent effects, ${ }^{20}$ and some of the more recent literature on earnings dynamics has modeled such earnings variation with a random-walk component (MaCurdy, 1982; Abowd and Card, 1989; Moffitt and Gottschalk, 1995). Third, most studies have found that the transitory component is serially correlated.

Fourth, several studies have found that the variance of the transitory component is a U-shaped function of age or experience. ${ }^{21}$

A generalization of equation (4) that encompasses these aspects of earnings dynamics is

$$
y_{i b t}=p_{t}\left[\alpha_{i b}+\beta_{i b}(t-b-26)+u_{i b t}\right]+\varepsilon_{i b t}
$$

where

$$
\varepsilon_{i b t}=\rho \varepsilon_{i b, t-1}+\lambda_{t} v_{i b t}
$$

and

$$
\operatorname{Var}\left(v_{i b t}\right)=\gamma_{0}+\gamma_{1}(t-b-26)+\gamma_{2}(t-b-26)^{2}+\gamma_{3}(t-b-26)^{3}+\gamma_{4}(t-b-26)^{4}
$$

We will refer to the model in equations (6)-(9) as our "base model." In equation (6), $\beta_{i b}$ is the deviation of the individual's idiosyncratic earnings growth rate from the average growth rate of his cohort (which already was subsumed in the $\mu_{b t}$ term in equation (1)). This individual-specific growth rate $\beta_{i b}$ is expressed as a coefficient of years since age 26 , so the variance in the individual-specific intercept $\alpha_{i b}$ reflects variance across individuals' earnings profiles as of age

\footnotetext{
${ }^{19}$ See Baker (1997) and the references therein. This finding of growth heterogeneity is to be expected, since the sources of life-cycle earnings growth -- such as human capital investment and schemes to elicit work effort -presumably do vary across individuals.

${ }^{20}$ One good example is the earnings losses suffered by displaced workers. See Jacobson, LaLonde, and Sullivan (1993) and Stevens (1997). Another example, stressed by Farber and Gibbons (1996), is the wage impact of the arrival of new information about workers' productivities.

${ }^{21}$ See Gordon (1984), for example.
} 
26 , and the variance in $\beta_{i b}$ influences how the variance across earnings profiles evolves after age 26. We will denote the variance of $\beta_{i b}$ as $\sigma_{\beta}^{2}$ and the covariance between $\alpha_{i b}$ and $\beta_{i b}$ as $\sigma_{\alpha \beta}$. If workers' choices about human capital investment involve trade-offs between early earnings levels and opportunities for subsequent earnings growth, $\sigma_{\alpha \beta}$ may be negative (Mincer, 1974; Lillard and Weiss, 1979; Hause, 1980).

In equation (7), which specifies a random-walk component in earnings growth after age $26,{ }^{22} r_{i b t}$ is a "white noise" innovation with variance $\sigma_{r}^{2}$. The random-walk innovation $r_{i b t}$, unlike the transitory innovation $v_{i b t}$ in equation (8), accommodates any permanent re-ordering of workers in the earnings distribution. One way to distinguish the random-walk component from the heterogeneous-growth component is that the former implies that the cross-sectional log earnings variances should rise linearly over the life cycle, while the latter implies a quadratic pattern. Equation (8) incorporates serial correlation of the transitory component via a first-order autoregressive process generalized to include year-specific factor loadings on the innovation $v_{i b t}$. This specification assumes that, if year $t$ is a year with unusually large innovations in the transitory earnings component (e.g., a recession year), the impact on the transitory variance in subsequent years dies out gradually. In addition, equation (9) allows the variance of $v_{i b t}$ to be a quartic function of age. $^{23}$

While this model imposes a great deal of structure on earnings dynamics, it significantly generalizes previous models by allowing for multiple sources of nonstationarity (with respect to

\footnotetext{
${ }^{22}$ Any such growth up through age 26 is subsumed in the $\alpha_{i b}$ term.

${ }^{23}$ While lower-order polynomials are sufficient in some of the models we estimate, the quartic is adopted for comparability across specifications. We also have tried extending our $\mathrm{AR}(1)$ specification in equation (8) to an $\operatorname{ARMA}(1,1)$ specification. See the discussion in footnote 24 .
} 
both calendar time and stage of life cycle). Like the models of Moffitt and Gottschalk (1995) and Haider (1998), it goes beyond earlier models by allowing for changes over calendar time in both the persistent and transitory components of earnings inequality. The model also extends Haider's by incorporating age-related heteroskedasticity of the transitory variance and a random-walk component. Relative to Moffitt and Gottschalk's preferred model, it adds both age variation in the transitory variance and heterogeneity in growth rates. Because previous researchers have had to rely on U.S. panel surveys with relatively small sample sizes, they have been unable to identify models with many sources of nonstationarity, and they therefore have had to make arbitrary choices about which varieties to include. For example, they have included either a random walk or heterogeneous growth, but not both. Our access to a large sample observed over many years enables us to identify richer models and to examine empirically which sources of nonstationarity play important roles in the earnings process. Consequently, in addition to generating evidence about the nature of growing earnings inequality in Canada, our study also responds to Atkinson, Bourguignon, and Morrisson's (1992) comment that distinguishing among competing models of earnings mobility "is important and tests of alternative specifications should be conducted. However, we have found few tests of that type in the literature we have reviewed."

\section{B. Estimation Methods}

We begin by estimating $\mu_{b t}$ in equation (1) with the sample mean log earnings for cohort $b$ in year $t$. We then treat the deviation of observed log earnings $Y_{i b t}$ from that mean as our measure of $y_{i b t}$. This simple "de-meaning" procedure adjusts for year, age, and cohort effects on average earnings in a less restrictive way than the preliminary regressions typically used, which 
assume that the age and cohort patterns within any year can be well approximated by a low-order polynomial in age or experience.

Next, for each of our nineteen sample cohorts (born 1924/25 through 1960/61), we construct the sample autocovariance matrix of $y_{i b t}$. For the nine cohorts observed for the entire 1976-1992 sample period, these are $17 \times 17$ matrices; the matrices for the other cohorts have smaller dimensions. (At the beginning of Section IV, we will display and discuss these matrices for a few selected cohorts.) Then we list the distinct elements of the sample autocovariance matrix for cohort $b$ in a vector $C_{b}$, which contains $153=(17 \times 18) / 2$ elements for each of the nine cohorts observed for the full sample period and fewer elements for the others. For purposes of standard error estimation, we also construct the matrix of fourth sample moments for each cohort.

We stack the nineteen $C_{b}$ vectors into an aggregate vector $C$, which contains a total of 2077 sample moments. These are the data to which we fit the model of earnings dynamics described above. We estimate the model's parameters by generalized method-of-moments (GMM); that is, by minimizing the distance between the observed sample moments in $C$ and the corresponding population moments implied by our model.

In particular, write the population analog to $C$ as $C^{*}$ and express our model's moment restrictions as $C^{*}=f(\theta)$ where $\theta$ is the vector containing all the parameters in our model. For example, our model in equations (6)-(9) implies that one element in $C^{*}$, the variance of $y_{i b t}$ in 1986 for the cohort born in $1950 / 1951$, is

$$
\begin{array}{r}
\operatorname{Var}\left(y_{i, 1950 / 51,1986}\right)=p_{1986}^{2}\left(\sigma_{\alpha}^{2}+100 \sigma_{\beta}^{2}+20 \sigma_{\alpha \beta}+10 \sigma_{r}^{2}\right)+\rho^{2} \operatorname{Var}\left(\varepsilon_{i, 1950 / 51,1985}\right) \\
+\lambda_{1986}^{2}\left(\gamma_{0}+10 \gamma_{1}+100 \gamma_{2}+1,000 \gamma_{3}+10,000 \gamma_{4}\right)
\end{array}
$$

where 10 and its multiples appear because we count this cohort as 10 years past age 26 in 1986. 
As ugly as this expression is, writing it out here serves at least two purposes. First, its complexity makes clear why we are not writing out the rest of the moments! Second, the dependence of the cohort's overall 1986 variance on its transitory variance in 1985 illustrates that the autoregressive process in equation (8) induces a recursive structure in the moments. If one traces the recursion back to the first year of the cohort's sample period (in this instance 1976), this raises the question of what the cohort's transitory variance is in that year. In the previous literature on earnings dynamics, it has been common to restrict the initial transitory variance to be the same for individuals of different ages. In our richer model, which recognizes that earnings volatility varies across cohorts because they are at different stages of the life cycle and have lived through different times, this restriction becomes untenable. We therefore treat the initial transitory variances of the nineteen cohorts as nineteen additional parameters to be estimated. ${ }^{24}$ Once $C^{*}=f(\theta)$ is specified, then GMM chooses $\hat{\theta}$ to minimize a distance function

$$
D=[C-f(\hat{\theta})]^{\prime} W[C-f(\hat{\theta})]
$$

where $W$ is a positive definite weighting matrix. The asymptotically optimal choice of $W$ is the inverse of a matrix that consistently estimates the covariance matrix of $C$. As explained by Altonji and Segal (1996) and Clark (1996), however, this approach can produce seriously biased estimates of $\theta$ in finite samples. We therefore follow the practice of the most recent literature and use the identity matrix as the weighting matrix. This approach, often called "equally weighted minimum distance estimation," just amounts to using nonlinear least squares to fit $f(\hat{\theta})$ to $C$.

\footnotetext{
${ }^{24}$ These cohort effects turn out to be important to the specification of the other parts of the transitory component. An ARMA $(1,1)$ extension of equation (8) can be supported if the cohort effects are treated symmetrically in the persistent and transitory components; that is, if the model either excludes or includes cohort effects in both components. In a model such as equations (6)-(9), where the cohort effects appear in only one component, the ARMA specification either does not converge or converges to a solution with negative estimates of some variance
} 
Finally, we use standard methods for estimating the covariance matrix of $\hat{\theta}$ on the basis of the fourth moments in the sample. ${ }^{25}$

\section{$\underline{\text { IV. Results }}$}

In lieu of deluging the reader with all 2077 sample moments, in Tables 3 and 4 we display the sample autocovariance matrices for just the cohorts born in 1926/27, 1942/43, and 1958/59. For all three cohorts (as well as the other sixteen not shown), the autocorrelation patterns in the upper right triangles of the matrices are similar to those reported in U.S. studies based on the Panel Study of Income Dynamics. Like Baker (1997) and Haider (1998), we find autocorrelations of around 0.8 at the first order, followed by gradual declines at higher orders. ${ }^{26}$

Because these three cohorts are at different stages of the life cycle during our 1976-1992 sample period, they illustrate important life-cycle patterns in earnings dynamics as well as some salient trends and cyclical patterns. The 1958/59 cohort, which is in its mid twenties in its first years in the sample, initially shows very large variances (on the main diagonal), which subsequently decline as the cohort settles into its mature career path. The lower autocorrelations displayed by this young cohort suggest that its higher variances are driven at least partly by high transitory variation. At the other end of the life cycle, the 1926/27 cohort shows rising variances as it approaches retirement age during its last years in the sample. These obvious patterns suggest the importance of including age-varying parameters in econometric models of earnings dynamics.

terms. Consistent with the evidence in Haider (1998), we find that our decompositions are not sensitive to the choice of this part of the model.

${ }^{25}$ See Chamberlain (1984) for a general discussion of GMM estimation and inference, and see the appendix to Abowd and Card (1989) for a detailed application to earnings dynamics models.

${ }^{26}$ We also have calculated sample autocovariance matrices for the first difference of $y_{i b t}$. These show autocorrelation patterns quite similar to those reported in Abowd and Card (1989) and Baker (1997). 
The year effects apparent in these matrices echo the patterns already discussed in connection with Table 2 and Figures 1 and 3. The sample variances rise dramatically with the 1982 recession and then recede a little in the late 1980 's before rising to new heights during the recession of the early 1990 's. The upper-right triangles of the matrices display one more pattern not visible in the earlier tables and figures -- there is not a striking secular trend in the autocorrelations. As explained in Section III, an increase in only the transitory variance component would cause the autocorrelations to decline, and an increase in only the persistent component would make them rise. A complete absence of trend in the autocorrelations would signify that the transitory and persistent components grew in equal proportions. Although the autocorrelation trend is not strong enough to be visible to the naked eye, a subtle trend may be present. Pooling all the autocorrelations for all cohorts and years, we have performed least squares estimation of the regression of the $\log$ of the autocorrelation between years $t$ and $s$ on a linear time trend variable, the unemployment rates in both years $t$ and $s$, a cubic in age, and fixed effects for the order of the autocorrelation. The estimated coefficient of the linear trend variable is 0.0013 with an estimated standard error of 0.0006 . The small magnitude of the estimated upward trend in the autocorrelations suggests that the rise in earnings inequality was generated by increases in both the transitory and persistent components, but there is some initial evidence that the persistent component grew by a marginally larger proportion.

To investigate these patterns more formally, we proceed to GMM estimation of the earnings dynamics model laid out in Section III. Table 5 shows the resulting estimates. In the first two columns are the parameter estimates and associated standard error estimates for the base model described in equations (6)-(9). Recall that this model incorporates a persistent component, composed of terms capturing individual-specific heterogeneity in the age/earnings profile as well 
as a random walk, plus a transitory component following an AR(1) process with age-based heteroskedastic innovations. Furthermore, each component's variance is shifted over time by a separate year-specific factor loading.

The estimates of $\sigma_{\alpha}^{2}$ and $\sigma_{\beta}^{2}$ in the first two rows express the heterogeneity in the intercept and slope of the age/earnings profile. They are generally smaller than the estimates found in studies of U.S. men. For example, our estimated standard deviation in earnings growth rates, $\hat{\sigma}_{\beta}=\sqrt{0.000090}=0.0095$, is a bit less than half of the most comparable estimates in Baker (1997) and Haider (1998). Baker and Haider, however, do not allow for a random-walk component, age-related heteroskedasticity in the transitory innovations, or differences across cohorts in their initial transitory variances, so all of the age structure in earnings dispersion necessarily gets loaded into the growth heterogeneity part of their models. Our significantly positive estimate of $\sigma_{r}^{2}$ in the seventh row indicates that the random-walk component also plays a role, and, as will be seen below, our results also point to substantial age-related heteroskedasticity in the transitory component.

Nevertheless, even our smaller estimate of $\sigma_{\beta}$ is both statistically and substantively significant. It implies that a worker with a growth rate one standard deviation above the mean would accumulate a 10 percent earnings advantage over the course of a decade. As in several previous studies (Lillard and Weiss, 1979; Hause, 1980; Baker, 1997; Haider, 1998), our estimate of $\sigma_{\alpha \beta}$ in the third row is significantly negative, corresponding to a trade-off between earnings early in the career and subsequent earnings growth.

In the seventeen rows starting with the eighth, we report the estimates of the year-specific factor loadings on the persistent component. For identification, the parameter for 1976 is 
normalized to equal 1 . The estimated factor loadings are a little above 1 in the years immediately after 1976, and then they increase sharply in the recession of 1982. There is a gradual decay over the expansion of the late 1980's and then another sharp increase in the recession of the early 1990's. The countercyclicality of the estimated factor loadings is consistent with the U.S. evidence that the annual work hours of low-wage workers are especially sensitive to the business cycle (Solon, Barsky, and Parker, 1994). The upward secular trend in the estimated factor loadings, foreshadowed by the patterns in the empirical autocovariance matrices reported in Tables 3 and 4, suggests that the persistent component plays an important role in the increase in earnings inequality over the period. Even though the previous literature reports that the return to education in Canada did not increase appreciably over this period, more generally the return to persistent worker attributes did trend upwards. This finding accords with Morissette and Berube's (1996) result that the dispersion in earnings summed over ten years increased from 1975-1984 to $1984-1993$.

In the next section of the table, we report the estimated parameters for the transitory component. First are the estimates of the "initial variances," which capture the accumulation of the transitory process up to the start of the sample period for each cohort. As was shown in Table 1, age in the initial year (1976) declines monotonically for cohorts $1924 / 25$ through 1950/51. In turn, the estimated initial variances for these cohorts display a vaguely U-shaped pattern, although there are spikes for some of the middle cohorts. The estimated initial variances for cohorts $1950 / 51$ through $1960 / 61$ document how the accumulation of the transitory process changed for 26-year-olds over the period. The clear message here is that dispersion has been increasing, as the variance estimates more than double from 1976 (cohort 1950/51) to 1986 (cohort 1960/61). 
In the next block are the estimates of the autoregressive parameter $\rho$ and the parameters of the quartic in age for the variance of the innovations to the transitory process. Our $\hat{\rho}=0.540$ is quite similar to Baker and Haider's most comparable estimates. The estimated parameters of the age quartic imply the profile shown in Figure 4. There is an initial decline in the variance of the innovations as it falls more than 50 percent from the mid twenties to the early forties. As was suggested above, the variance flattens out in mid-age. Finally, it rises in the fifties although not to the levels observed at the beginning of the age profile. This pattern is consistent with other evidence in the literature (Gordon, 1984) and points to the importance of accounting for the systematic influence of age on transitory innovations to earnings.

In the final block of the table, we report the estimated year-specific factor loadings on the transitory innovation. Here we must use the normalization that the parameter for 1977 equals 1 , since the variance of this component in 1976 is left unrestricted to identify the initial variances of the cohorts . Not surprisingly, here we see more cyclical variation than was apparent in the factor loadings for the persistent component, with the transitory factor loadings rising more dramatically in the recession of $1982 .{ }^{27}$ There is next some recovery from the recession, a fairly flat profile over the expansion of the late 1980's, and finally another sharp increase in the recession of the early 1990's.

Just plotting the time series of $p_{t}$ and $\lambda_{t}$ is not sufficient to give a full characterization of the relative contributions of the persistent and transitory components to increases in earnings inequality. The relative roles of the two components depend not only on these two factor loadings but also on the relative magnitudes of the factors that they load, the initial transitory variances, and the autoregressive parameter. Therefore, in Figure 5 we use our estimates of all 
these parameters to decompose our estimated model's predicted variance of log earnings into its persistent and transitory components, holding age constant to abstract from any life-cycle considerations. The decomposition is performed for males 40 years old, which is approximately the midpoint of the ages observable in our sample, and it tells the story of individuals who in turn should be in the middle of their working careers. ${ }^{28}$ In moving from year to year, the factor loadings on the two components change, as does the initial variance used in generating the transitory variance up to age $40 .^{29}$

The first thing to note in Figure 5 is the increase in the total variance, primarily in steps corresponding to the recessions over the sample period. This, of course, duplicates the pattern seen earlier in Figure 1 (and in previous Canadian studies based on the Survey of Consumer Finances). The novel feature of Figure 5 is its decomposition of the total variance into persistent and transitory components. In the early years of the sample period, the persistent component accounts for about 70 percent of the inequality in annual earnings. The two components move remarkably similarly over time. Both components rise substantially in the recession starting in 1982, settle down during the recovery at a higher level than before the recession, and then leap to new heights in the recession of the early 1990's. Because the transitory and persistent components increase by similar absolute magnitudes from 1976 to 1992, the proportional share of the persistent component is slightly lower in 1992 than in 1976.

\footnotetext{
${ }^{27}$ Haider (1998) reports a similar result for the United States.

${ }^{28} \mathrm{We}$ also have performed the decomposition for ages 32 and 50 . The results for age 50 are qualitatively very similar to those for age 40 . The results for age 32 assign a somewhat larger portion of the growth in earnings inequality to the transitory component.

${ }^{29}$ In fact, the initial variance changes every two years, corresponding to the cohort estimates reported in Table 5 . For example, in 1976 we have a direct estimate of the variance of the transitory component for males aged 40 in the initial variance for cohort $1936 / 37$. In 1978 , we use the initial variance for cohort $1938 / 39$, whose members are 40 in this year.
} 
A pairwise comparison of 1976 and 1992, however, is inadequate for trend analysis because business-cycle conditions were not identical in the two years. To control for businesscycle effects in an analysis spanning all seventeen years, we apply least squares to estimate timeseries regressions of the persistent and transitory components on a linear time trend and the unemployment rate. The results are reported in Table 6. The point estimates suggest that the persistent component contributed a marginally larger absolute amount to the upward trend in earnings inequality. The estimated coefficients of the unemployment rate indicate a slightly larger cyclical sensitivity in the transitory component. That said, the overall inference is consistent with the impression from Figure 5 that the two series show similar cyclical movements and contribute similar amounts to the secular increase in annual earnings inequality.

Our base model nests and extends most of the specifications used in U.S. studies. U.S. researchers, who have had to rely on relatively small-scale panel surveys, have had to settle for estimating simpler and more restrictive models than the base model used here. For example, even though life-cycle variation in the transitory variance component is both economically plausible and empirically supported by some earnings dynamics research, the recent U.S. studies that have decomposed the inequality trend into persistent and transitory components have assumed away that source of nonstationarity in the earnings process. Similarly, these studies have assumed either heterogeneity in earnings growth rates or a random-walk process, but not both. Assuming away one or the other is unfortunate because there are good reasons to expect both to be present. It is hard to believe that the sources of earnings growth, such as human capital investment and effort-elicitation schemes, operate with identical force for all individuals. It is just as hard to believe there is no such thing as earnings shocks with permanent effects (e.g., job displacements, disabling injuries, and new information about workers' skills). 
The fact that our base model encompasses these different aspects of earnings dynamics allows us the opportunity to ask two related methodological questions. First, do our data reject the restrictions imposed in the U.S. literature? Second, if so, does it matter? Is the imposition of false restrictions innocuous for addressing the issues at hand, or does it distort the analysis of those issues? In Tables 7 and 8, we explore both questions by estimating a series of restricted models.

In the first two columns of Table 7, we examine the implications of assuming away permanent earnings shocks by estimating a model with no random walk (i.e., with $\sigma_{r}^{2}=0$ ). It is clear that this "restricted model 1" is statistically indefensible, as the estimate of $\sigma_{r}^{2}$ in Table 5 is highly significant in both the statistical and economic senses. But does the imposition of the false restriction that $\sigma_{r}^{2}=0$ make much difference for characterizing other aspects of earnings dynamics? Comparing the results in Table 7 to those in Table 5 reveals that assuming away the random walk leads to a larger estimate of the autoregressive parameter $\rho$ and to smaller estimates of $\sigma_{\alpha}^{2}$ and $\sigma_{\beta}^{2}$. Also the estimated covariance of $\alpha$ and $\beta$ now becomes positive although statistically insignificant. For purposes of the present paper, we are most interested in how the restriction affects the decomposition of earnings inequality into persistent and transitory components. Therefore, in Figure 6 we present the decomposition for restricted model 1 so that we can compare it to the decomposition shown in Figure 5 for the base model. Note first that, with the restricted model, the persistent component makes up relatively less of total inequality at any point in time. Whereas the persistent component represented roughly two-thirds of total inequality in Figure 5, in Figure 6 the proportion varies between 50 and 60 percent. The implication is a higher degree of mobility in the earnings distribution, although the larger estimate 
of $\rho$ implies that transitory churning has longer persistence. A second difference is that the two components seem less synchronous than in Figure 5. The persistent component exhibits greater trend increase leading up to the 1982 recession, while the transitory component displays greater increase thereafter. In Table 6 we report the results of time-series regressions of each component on the unemployment rate and a linear trend. Relative to the base model, in the restricted model the two components trade roles in their contributions to the inequality trend. It is now the transitory component that makes the marginally larger contribution to rising inequality.

The models actually used in previous studies are more restrictive than this example, and further restrictions can have larger effects on inference. In the next two columns of Table 7 ("restricted model 2"), we report estimates of a specification that, relative to the base model, assumes away both growth-rate heterogeneity in the persistent component and age-related heteroskedasticity in the transitory innovation. The Wald test statistics reported in the first panel of Table 8 make clear that these restrictions not only are economically implausible, but also are statistically indefensible with our data. The test statistic for the null hypothesis of no growth-rate heterogeneity $\left(\sigma_{\beta}^{2}=0\right.$ and $\left.\sigma_{\alpha \beta}=0\right)$ has a p-value that is zero to at least four decimal places. So does the test statistic for the null hypothesis of no age-related heteroskedasticity in the transitory innovation $\left(\gamma_{1}=\gamma_{2}=\gamma_{3}=\gamma_{4}=0\right)$. Nevertheless, these restrictions are of considerable interest because they are imposed in the preferred model in Moffitt and Gottschalk's (1995) influential study. We therefore would like to know whether these restrictions are innocuous for purposes of identifying trends in earnings inequality.

Comparing the parameter estimates for this specification to those for the base model, again some change very little, and others change a lot. To explore how much the changes matter, 
in Figure 7 we plot the decomposition of total predicted inequality into persistent and transitory components. Here there are some major differences from Figures 5 and 6 . The persistent component accounts for a little less than two-thirds of the total variance at the beginning of the sample period. Unlike the preceding figures, however, Figure 7 shows the transitory component increasing by more than the persistent component so that, by the end of the sample period, the transitory component is just as large. This observation is formalized in time-series regressions reported in Table 6. The results suggest the transitory component plays the dominant role in trend increases in inequality. Therefore, while the estimates from the more general model indicate that increases in the persistent component contributed marginally more to the growth in earnings inequality, this simpler model imposing clearly false restrictions attributes most of the inequality growth to the transitory component.

To explore further the implications of the choice between allowing for heterogeneous growth rates or a random walk, in the last columns of Table 7 we report estimates for "restricted model 3." In contrast to restricted model 2, this model incorporates heterogeneous growth rates instead of a random walk, while continuing to assume away age-related heteroskedasticity in transitory innovations. Once again, relative to the base model this model is statistically indefensible, but it is of interest because it is comparable to the preferred model in Haider's (1998) study. The resulting decomposition of total inequality is depicted in Figure 8 and Table 6. Here the results are much closer to those for the base model, though they still imply a somewhat larger role for the transitory component in rising inequality. The distinguishing feature between restricted models 2 and 3 is that the former accommodates only linear life-cycle growth in persistent earnings dispersion (through the unit root) while the latter can accommodate nonlinear 
effects (through the age profile). This distinction turns out to have a considerable impact on the decomposition.

What do these results imply for the U.S. evidence on persistent versus transitory components of rising earnings inequality? Until such time as U.S. data comparable to our Canadian data become available to researchers, it will be impossible to say for sure whether our results would be replicated in the U.S. context. Our specification analysis, however, is suggestive of the possibility that the U.S. evidence has been distorted by the model restrictions necessitated by small data sets. With the Canadian data, we have found that assuming away some aspects of nonstationarity in life-cycle earnings dynamics leads to exaggeration of the role of the transitory component in rising cross-sectional earnings inequality, and it understates the role of the persistent component. This distortion is particularly serious in the case of Moffitt and Gottschalk's (1995) preferred specification.

This discussion, of course, begs the question of whether our own base model also imposes false restrictions that affect inference. In defense of the base model, we reemphasize that it incorporates most of the lessons of previous research, and we also note the usual trade-off between the greater generality of a more complex model and its lesser parsimony and intelligibility. Nevertheless, it is very important to explore the implications of extending the model further, and we do so in Table 5.

One conceptually straightforward extension of our base model is to allow for quadratic heterogeneity in growth rates. If workers differ in the steepness of their earnings/age profiles, why not in the curvature as well? Baker (1997) reports some evidence for heterogeneity in curvature, and Lillard and Reville (1999) explain why this pattern ought to be expected. While workers differ initially in the intensity of their human capital investment, all of them should stop 
investing by the ends of their careers. Therefore, those with the steepest earnings growth earlier in their careers also should display more curvature in their earnings/age profiles.

To incorporate this possibility, we embellish equation (6) in our base model by adding an individual-specific coefficient $\psi_{i b}$ for the square of age since 26 . This introduces three new parameters -- the variance of $\psi_{i b}$ and its covariances with $\alpha_{i b}$ and $\beta_{i b}$-- into our model of earnings covariances. Our results from estimating this "extended model 1" are shown in the third and fourth columns of Table 5. Perhaps surprisingly, the data do not seem to care much for adding only this embellishment to the base model. The estimated variance of $\psi_{i b}$ is insignificantly negative. As shown in the second panel of Table 8, a Wald test of the joint hypothesis that all three new parameters are zero fails to reject at the 0.10 significance level. Adding the new parameters to the model has very little effect on the other parameter estimates or on the decomposition of earnings inequality into its persistent and transitory components.

Another natural extension of the base model is to supplement the cohort effects already incorporated into the transitory component with cohort effects in the persistent component. The possibility of inter-cohort variation in skill dispersion usually has been downplayed in the U.S. literature on inequality trends. The introduction to Juhn, Murphy, and Pierce's (1993) important study, for example, says, "we view the trend toward increased inequality not in terms of increased dispersion in unobserved ability (or increased measurement error etc.) but rather as an increasing market return to skill." 30

Nevertheless, we have two reasons for wanting to entertain the possibility of cohort differences in the persistent component of earnings variation. First, we know of no basis for 
believing such cohort differences are absent, and there is some evidence they are present. While it is difficult, if not impossible, to adduce convincing evidence with respect to dispersion in unobserved ability, there is clear-cut variation across Canadian cohorts in the distribution of at least one measurable trait, namely years of education. In each of three Canadian censuses (1976, 1981, and 1986), we have measured the variance of educational attainment among men who worked in the reference week and belonged to a birth cohort appearing in our T-4 sample for that year. Education measurement differs somewhat across censuses, and the appendix to this paper provides details of the construction of our education variable. The results in Table 9 indicate that the variance in years of education has declined dramatically between earlier and more recent cohorts.

Second, even if skill dispersion did not vary across cohorts in the population, our sampling scheme might induce inter-cohort variation in our sample. We require individuals to have consecutive years of positive earnings in the years between 1976 and 1992 in which they satisfy the requirement of being 24-59 years of age. For older cohorts this requires consecutive years of positive earnings in the later stage of life, while for younger cohorts the consecutive years of earnings are required as early as the mid twenties. It is easy to imagine that the types of individuals who string together years of positive earnings early in life differ, in persistent ways, from those who accomplish this feat later in the life cycle. This is another reason to question our base model's assumption that $\sigma_{\alpha}^{2}$ is the same for all cohorts.

Therefore, in "extended model 2" we introduce cohort-specific values of $\sigma_{\alpha}^{2}$. The resulting estimates are shown in the last two columns of Table 5. The first thing to note is that

\footnotetext{
${ }^{30}$ Juhn, Murphy, and Pierce (1993) present compelling evidence that rising inequality has stemmed in large part from "an increasing market return to skill," but, as they acknowledge, their evidence cannot rule out effects from
} 
the data do seem to favor the addition of the new parameters. As shown in the third panel of Table 8, a Wald test of the base model's restriction that all cohorts have the same $\sigma_{\alpha}^{2}$ resoundingly rejects that restriction. The pattern shown by the point estimates is a systematic decline across cohorts in their persistent heterogeneity until a leveling-out appears starting with the cohort born in 1948/49. As shown in Table 9, this pattern coheres somewhat with the decline between earlier and more recent cohorts in the variance of educational attainment. The correlation between a cohort's variance in educational attainment and our estimate of its $\sigma_{\alpha}^{2}$ exceeds 0.8 regardless of which census we use to measure education.

The addition of the new parameters induces some notable changes in the estimates of other parameters of the model. First, the data now become more enamored of the quadratic specification of heterogeneity in earnings growth. The estimate of $\sigma_{\psi}^{2}$ now becomes significantly positive, and a Wald test of the joint hypothesis that the three parameters associated with quadratic heterogeneity are all zero rejects with a p-value of zero to at least four decimal places. In accordance with Lillard and Reville's (1999) analysis, the estimated covariance between $\psi_{i b}$ and $\beta_{i b}$ is now significantly negative -- workers with rapid early earnings growth experience greater curvature later on.

Second, the estimates of the higher-order parameters in the age quartic for heteroskedasticity in transitory innovations become larger. We graph the implied profile in Figure 9. Relative to Figure 4 , the transitory variance declines more quickly with age, and there is a stable, fairly flat segment between ages 35 and 52 .

between-cohort changes in skill dispersion. 
Third, and more importantly for purposes of this paper, the estimates of the factor loadings on the persistent and transitory components change quite dramatically. Relative to the base model, the upward time trend in the loadings on the persistent component is now considerably larger, while the loadings on the transitory component display greater cyclical variation and less trend. This latter point can be seen by comparing the two models' estimates of $\lambda_{t}$ for the late 1980 's, when the economy was in a sustained and wide-ranging expansion. The estimates from extended model 2 are near 1.0, last seen in the late 1970's during another expansionary period. In contrast, the estimates from the base model for these years display a large trend increase relative to the late 1970 's.

With respect to the persistent component, extended model 2 characterizes rising earnings inequality as the net effect of two opposing developments. On one hand, the greater homogeneity of the more recent cohorts has been a force toward more equal earnings. But this force has been much more than offset by an upward trend in the factor loadings, which might be interpreted as a rise in the returns to skill. In the base model, which assumes away cross-cohort changes in heterogeneity, the estimated factor loadings end up reflecting the net effect of these two forces. In extended model 2, which separates the two forces, the factor loadings are freed up to reflect only the rapid rise in returns to skill.

In Figure 10, we depict the extended model's implications for the decomposition of inequality into its persistent and transitory components. The figure portrays the net effects of the two opposing forces in persistent inequality. That is, as new cohorts arrive at age 40 , we allow both the persistent factor loadings to increase and $\sigma_{\alpha}^{2}$ to decrease. The figure is fairly similar to Figure 5 for the base model, but despite the greater homogeneity of the more recent cohorts, Figure 10 shows an even greater role for the persistent component in accounting for the increase 
in overall earnings inequality. This is formalized in the time-series regressions in Table 6.

Compared to the base model, extended model 2 shows a larger estimated trend coefficient for the persistent component and a smaller one for the transitory component. We see even greater dissimilarity in comparisons of the extended model to the restricted models estimated in Table 7. The restricted models' understatement of the role of the persistent component in rising inequality and exaggeration of the role of the transitory component are accentuated in comparison to extended model 2.

Would further experimentation lead to still more changes in inference? We have explored two extensions of extended model 2 and found that our results are not sensitive in these dimensions. The first extension is to specify cohort-specific parameters for the entire age profile of the persistent component, restricting the profile to be linear to keep the model manageable. This is just a simple extension of the argument that led to the cohort-specific estimates of $\sigma_{\alpha}^{2}$. The second is to specify separate factor loadings on the random-walk portion of the persistent component. The argument here is that the sorts of events that lead to unit roots in earnings are very different from the human capital investments that lead to heterogeneous growth rates, and the evolution of these two types of effects over the 1980's might be different. The trend decompositions for these models, however, turn out to be very similar to the decomposition for extended model 2. In each case, the persistent component still makes the larger contribution to the upward trend in inequality. ${ }^{31}$

\footnotetext{
${ }^{31}$ The parameter estimates for these models are available from the authors on request. For the model with cohortspecific age profiles in the persistent component, time-series regressions (as in table 6) lead to estimated time trend coefficients of $0.0043(0.0009)$ for the persistent component and $0.0013(0.0004)$ for the transitory component. The corresponding estimates for the model with the separate factor loading on the random walk are 0.0038 $(0.0005)$ and $0.0018(0.0005)$ respectively. The factor loadings on the random walk do display a different pattern than the loadings on the age profile of the persistent component. They decline in recessions, peak in expansions,
} 
To summarize, our results indicate that Canada's increase in earnings inequality has stemmed from increases in both the persistent and transitory components of earnings variation. The results from our preferred models suggest that the persistent component has played at least a somewhat larger role. This means that, to an important extent, the growth in cross-sectional inequality reflects a widened gap between the chronic haves and the chronic have-nots. Our results contrast somewhat with the U.S. literature, which has concluded that increases in the persistent and transitory components have been about equally important. This contrast seems anomalous at first because the returns to education have increased less in Canada than in the United States. Our specification analyses, however, reveal that the contrast may be at least partly an artifact of specification errors in the U.S. literature. When we use our Canadian data to test the restrictions imposed in the U.S. literature, we reject the restrictions. We also find that imposing these evidently false restrictions shifts the decomposition of the increase in earnings inequality towards the transitory component.

\section{$\underline{\text { V. Conclusions }}$}

Using an extraordinary data set drawn from longitudinal income tax records, we have verified that earnings inequality in Canada grew substantially over our sample period of 19761992, and we have decomposed this growth in inequality into its persistent and transitory components. Like some of the U.S. studies cited in our introduction, we have found that the rise in inequality has stemmed from upward trends in both components. Thus, Canada's growth in annual earnings inequality signifies an increase in long-run inequality, as well as an increase in

and range between 0.93 and 1.17. The estimated factor loadings for the age profile of the persistent component are very similar to those reported for extended model 2. 
earnings instability. Our estimates from our preferred models suggest that the increase in the persistent component may have played a somewhat larger role.

What has caused the increases in both long-run inequality and instability is an important subject for continuing research. In the U.S. studies, the finding of increased persistent inequality was expected because the United States has experienced a large increase in the return to schooling. This increase has been thoroughly documented and has been attributed in large part to skill-biased technological change that has increased the relative demand for educated labor. ${ }^{32}$ In Canada, however, there has been little increase in the return to education, so it was less clear whether Canada's increase in annual earnings inequality reflects a rise in long-run inequality. Now that we have found that it does, it is natural to ask why long-run inequality has increased in Canada without much increase in the return to schooling. Freeman and Needels (1993) conjecture that the wage impact of increased relative demand for educated labor has been offset in Canada by a dramatic increase in the supply of college-educated labor. If other skill attributes (e.g., intelligence) have not undergone similar increases in supply, though, skill-biased technological change could still increase the returns to those skills. Perhaps this is why the persistent component of earnings inequality has increased in Canada despite little change in the return to schooling.

The increase in earnings instability is even more puzzling, both in the United States and Canada. While the U.S. literature has intensively studied the increased return to schooling, it has just begun to speculate about the sources of rising volatility in earnings. Gottschalk and Moffitt (1994), as well as their discussants, do discuss various possible explanations for the U.S. increase

\footnotetext{
${ }^{32}$ DiNardo, Fortin, and Lemieux (1996), however, stress that changes in unionization and the relative minimum wage also have contributed to the rise in wage inequality.
} 
in earnings instability, but they conclude, "We have not located any definitive explanation for the increased transitory variance." For example, they consider whether the large decline in the unionization of the U.S. work force has played an important role, but they find this could be "only a small part of the explanation." In Canada, de-unionization is even less promising as an explanation because union density has not declined nearly as much there as in the United States (Riddell, 1993).

Another possible source of increased earnings instability is a decline in job stability. The U.S. evidence, however, does not point to a clear-cut trend in that direction. ${ }^{33}$ Similarly, the two Canadian studies of which we are aware -- Heisz (1996) and Green and Riddell (1997) -- do not find a broad trend toward shorter job duration, but instead find an increasing prevalence of both very short and very long jobs. Whether this polarization in the job tenure distribution can possibly explain much of Canada's increase in earnings instability probably deserves some attention. ${ }^{34}$ Another possible factor, which seems to have been overlooked so far in the literature, is tax changes that have altered the incentives for income smoothing. ${ }^{35}$ As detailed in Shoven and Whalley (1992), both Canada and the United States adopted a complex series of tax changes during the 1980's. While some of these changes (such as the flattening of marginal tax rates) may have increased earnings volatility by reducing incentives for income smoothing, others (such as Canada's elimination of income averaging) cut in the other direction. As in the case of changes in the distribution of job tenure, the impact on earnings instability is not immediately obvious, but probably warrants further research.

\footnotetext{
${ }^{33}$ See Jaeger and Stevens (1998) and the references therein.

${ }^{34}$ Another empirical question relevant to this issue is whether the increased instability in annual earnings stems from increased instability in annual work hours or in hourly wages. Unfortunately, our data set does not permit a decomposition of annual earnings into its hours and wage components.
} 
The substantive focus of our paper has been on learning more (and raising additional questions) about the sources of Canada's increase in earnings inequality. Along the way, however, we also have tried to push the econometric envelope in the modeling of earnings dynamics. Thanks to the large size of our earnings panel, we have had the opportunity to estimate more general models than could be identified in previous research on earnings mobility.

For example, several recent studies have modeled the fanning out of a cohort's earnings distribution over the life cycle with either heterogeneous earnings growth or a random walk, but limited sample sizes have prevented these studies from incorporating both in the same model. We have succeeded in estimating the parameters of both of these aspects of the earnings process, and we have found that both are significant. This is a reassuring finding because there are good economic reasons to expect both aspects to be present. Persistent differences across individuals in their intensity of human capital investment, for example, ought to lead to heterogeneity in earnings growth. ${ }^{36}$ Job losses and other shocks that cause permanent earnings changes ought to generate a random-walk aspect in the earnings process. In addition, we have found that the volatility of transitory earnings innovations varies significantly with stage of the life cycle. When researchers specify models that arbitrarily rule out some of these factors, they run the risk of falsely attributing some of the nonstationarity apparent in earnings data to only those sources of nonstationarity that remain in their models.

The practical importance of these modeling choices is illustrated by our experiments with imposing restrictions commonly found in the U.S. literature on earnings dynamics and inequality

\footnotetext{
${ }^{35}$ We thank Joel Slemrod for raising this possibility and Jack Mintz for discussing it with us.

${ }^{36}$ It therefore is surprising that Abowd and Card's (1989) influential study claims an "absence of any permanent individual components of variance in the rate of growth of earnings or hours." As explained in Baker (1997), Abowd and Card fail to detect the heterogeneity of earnings growth because their samples are small and because they view the data only in first differences.
} 
trends. Not only do our data reject many of these restrictions, but imposing these apparently false restrictions sometimes generates important changes in substantive results. For example, we find with our data that imposing Moffitt and Gottschalk's (1995) restrictions of no heterogeneity in earnings growth rates and no age-related heteroskedasticity in transitory innovations ascribes a much larger share of the increase in earnings inequality to the transitory component. This raises the possibility that some of the findings in the U.S. literature have been distorted by the modeling restrictions necessitated by reliance on relatively small-scale panel surveys. Of course, the happiest response to this possibility would be to acquire better U.S. data that would enable estimation of less restrictive models. Until such time as that becomes possible, researchers need to be cognizant of the possible sensitivity of their results to arbitrary modeling choices, and they need to conduct and report checks of the robustness of their results across alternative specifications. 


\section{Appendix}

The variables capturing education differ somewhat across the 1976, 1981 and 1986 Canadian censuses. In the 1981 and 1986 censuses, some years of primary and secondary education are reported in ranges, and greater detail on years of post-secondary education is available. To construct a variable that is consistent across censuses, we measure years of education as the sum of years of primary/secondary, years of post-secondary university, and years of post-secondary non-university. Years of primary/secondary can take on the values 2, 6, and 9 through 13 . Years of post-secondary university can take on the values 0 through 6 . Years of post-secondary nonuniversity can take on the values 0 through 3 . 


\section{$\underline{\text { References }}$}

Abowd, John M., and David Card, "On the Covariance Structure of Earnings and Hours Changes," Econometrica, March 1989, 57, 411-45.

Altonji, Joseph G., and Lewis M. Segal, "Small-Sample Bias in GMM Estimation of Covariance

Structures," Journal of Business and Economic Statistics, July 1996,14, 353-66.

Atkinson, A. B., F. Bourguignon, and C. Morrisson, Empirical Studies of Earnings Mobility, Chur: Harwood Academic Publishers, 1992.

Attanasio, Ottavio, and Steven J. Davis, "Relative Wage Movements and the Distribution of Consumption," Journal of Political Economy, December 1996, 104, 1227-62.

Baker, Michael, "Growth Rate Heterogeneity and the Covariance Structure of Life-Cycle Earnings," Journal of Labor Economics, May 1997, 15, 537-79.

Bar-Or, Yuval, John Burbridge, Lonnie Magee, and A. Leslie Robb, "The Wage Premium to a University Education in Canada, 1971-1991," Journal of Labor Economics, October 1995, $13,762-94$.

Beach, Charles M., and Ross Finnie, "Polarization and Earnings Mobility among Workers in Canada, 1982-1994," unpublished, Queen's University, 1997.

Beach, Charles M., George A. Slotsve, and Francois Vaillancourt, "Inequality and Polarization of Earnings in Canada, 1981-1992," unpublished, Queen's University, 1996.

Beaudry, Paul, and David Green, "Cohort Patterns in Canadian Earnings: Assessing the Role of Skill Premia in Inequality Trends," unpublished, University of British Columbia, 1997.

Blackburn, McKinley L., and David E. Bloom, "The Distribution of Family Income: Measuring and Explaining Changes in the 1980s for Canada and the United States," in Small Differences That Matter: Labor Markets and Income Maintenance in Canada and the United States, ed. David Card and Richard B. Freeman, Chicago: University of Chicago Press, 1993.

Blundell, Richard, and Ian Preston, "Consumption Inequality and Income Uncertainty," Quarterly Journal of Economics, May 1998, 113, 603-40. 
Bound, John, and George Johnson, “Changes in the Structure of Wages in the 1980's: An

Evaluation of Alternative Explanations," American Economic Review, June 1992, 82, 71 392.

Buchinsky, Moshe, and Jennifer Hunt, "Wage Mobility in the United States," Working Paper No. 5455, National Bureau of Economic Research, 1996.

Chamberlain, Gary, "Panel Data," in Handbook of Econometrics, volume 2, ed. Zvi Griliches and Michael D. Intriligator, Amsterdam: North-Holland, 1984.

Clark, Todd, "Small-Sample Properties of Estimators of Nonlinear Models of Covariance Structure," Journal of Business and Economic Statistics, July 1996, 14, 367-73.

Cutler, David M., and Lawrence F. Katz, "Rising Inequality? Changes in the Distribution of Income and Consumption in the 1980's," American Economic Review, May 1992, 82, 546-51.

Davis, Steven J., "Cross-Country Patterns of Change in Relative Wages,” NBER Macroeconomics Annual, 1992, 7, 239-92.

DiNardo, John, Nicole M. Fortin, and Thomas Lemieux, "Labor Market Institutions and the Distribution of Wages, 1973-1992: A Semiparametric Approach," Econometrica, September 1996, 64, 1001-44.

DiNardo, John, and Thomas Lemieux, "Diverging Male Wage Inequality in the United States and Canada, 1981-1988: Do Institutions Explain the Difference?’ Industrial and Labor Relations Review, July 1997, 50, 629-51.

Farber, Henry S., and Robert Gibbons, "Learning and Wage Dynamics," Quarterly Journal of Economics, November 1996, 111, 1007-47.

Freeman, Richard B., and Karen Needels, "Skill Differentials in Canada in an Era of Rising Labor Market Inequality," in Small Differences That Matter: Labor Markets and Income Maintenance in Canada and the United States, ed. David Card and Richard B. Freeman, Chicago: University of Chicago Press, 1993.

Friedman, Milton, A Theory of the Consumption Function, Princeton: Princeton University Press, 1957.

Gittleman, Maury, and Mary Joyce, "Earnings Mobility and Long-Run Inequality: An Analysis Using Matched CPS Data,” Industrial Relations, April 1996, 35, 180-96. 
Gordon, Roger H., Differences in Earnings and Ability, New York: Garland, 1984.

Gottschalk, Peter, "Changes in Inequality of Family Income in Seven Industrialized Countries," American Economic Review, May 1993, 83, 136-42.

Gottschalk, Peter, and Robert A. Moffitt, "The Growth of Earnings Instability in the U.S. Labor Market," Brookings Papers on Economic Activity, 1994:2, 217-72.

Green, David A., and W. Craig Riddell, "Job Durations in Canada: Is Long-Term Employment Declining?" in Transition and Structural Change in the North American Labour Market, ed. Michael G. Abbott, Charles M. Beach, and Richard P. Chaykowski, Kingston: IRC Press, 1997.

Haider, Steven J., "Earnings Instability and Earnings Inequality of Males in the United States: 1967-1991," Chapter 2 in Econometric Studies of Long-Run Earnings Inequality, Ph.D. dissertation, University of Michigan, 1998.

Hause, John C., "The Fine Structure of Earnings and the On-the-Job Training Hypothesis," Econometrica, May 1980, 48, 1013-30.

Heisz, Andrew, "Changes in Job Tenure in Canada," Canadian Economic Observer, January 1996, 3.1-3.9.

Jacobson, Louis S., Robert J. LaLonde, and Daniel G. Sullivan, 'Earnings Losses of Displaced Workers," American Economic Review, September 1993, 83, 685-709.

Jaeger, David A., and Ann Huff Stevens, "Is Job Stability in the United States Falling?

Reconciling Trends in the Current Population Survey and Panel Study of Income Dynamics," Working Paper No. 6650, National Bureau of Economic Research, 1998.

Juhn, Chinhui, Kevin M. Murphy, and Brooks Pierce, "Wage Inequality and the Rise in Returns to Skill," Journal of Political Economy, June 1993, 101, 410-42.

Katz, Lawrence F., "Comments and Discussion," Brookings Papers on Economic Activity, 1994:2, 255-61.

Katz, Lawrence F., and David H. Autor, "Changes in the Wage Structure and Earnings Inequality," in Handbook of Labor Economics, ed. Orley Ashenfelter and David Card, Amsterdam: North-Holland, forthcoming.

Katz, Lawrence F., and Kevin M. Murphy, "Changes in Relative Wages, 1963-1987: Supply and Demand Factors," Quarterly Journal of Economics, February 1992, 107, 35-78. 
Kennedy, Bruce, "Mobility and Instability in Canadian Earnings," Canadian Journal of Economics, May 1989, 22, 383-94.

Lillard, Lee A., and Robert T. Reville, "Life Cycle Human Capital Investment: New Evidence on an Old Issue," unpublished, University of Michigan, 1999.

Lillard, Lee A., and Yoram Weiss, "Components of Variation in Panel Earnings Data: American Scientists 1960-70," Econometrica, March 1979, 47, 437-54.

MaCurdy, Thomas E., "The Use of Time Series Processes to Model the Error Structure of Earnings in a Longitudinal Data Analysis,” Journal of Econometrics, January 1982, 18, 83-114.

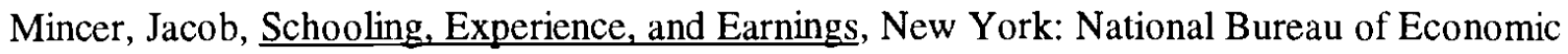
Research, 1974.

Moffitt, Robert A., and Peter Gottschalk, "Trends in the Autocovariance Structure of Earnings in the U.S.: 1969-1987,'” Working Paper No. 355, Department of Economics, Johns Hopkins University, 1995.

Morissette, Rene, "The Declining Labour Market Status of Young Men," unpublished, Statistics Canada, 1997.

Morissette, Rene, and Charles Berube, "Longitudinal Aspects of Earnings Inequality in Canada," unpublished, Statistics Canada, 1996.

Picot, Garnett, "Working Time, Wages and Earnings Inequality among Men and Women in Canada, 1981-93,” unpublished, Statistics Canada, 1996.

Richardson, David H., "Changes in the Distribution of Wages in Canada, 1981-1992," Canadian Journal of Economics, August 1997, 30, 622-43.

Riddell, W. Craig, "Unionization in Canada and the United States: A Tale of Two Countries," in Small Differences That Matter: Labor Markets and Income Maintenance in Canada and the United States, ed. David Card and Richard B. Freeman, Chicago: University of Chicago Press, 1993.

Shoven, John B., and John Whalley, ed., Canada-U.S. Tax Comparisons, Chicago: University of Chicago Press, 1992.

Solon, Gary, "Mobility within and between Generations," unpublished, University of Michigan, 1999. 
</ref_section> 
Solon, Gary, "Intergenerational Mobility in the Labor Market," in Handbook of Labor Economics, ed. Orley Ashenfelter and David Card, Amsterdam: North-Holland, forthcoming.

Solon, Gary, Robert Barsky, and Jonathan A. Parker, "Measuring the Cyclicality of Real Wages: How Important Is Composition Bias?” Quarterly Journal of Economics, February 1994, $109,1-25$.

Stevens, Ann Huff, "Persistent Effects of Job Displacement: The Importance of Multiple Job Losses," Journal of Labor Economics, January 1997, 15, 165-88. 
Table 1: Cohorts Included in the Working Sample

\begin{tabular}{lccc}
\hline Birth Year & Sample Size & Years Observed & Age in Initial Year \\
\hline $1924 / 25$ & 1219 & $1976-1982$ & 52 \\
$1926 / 27$ & 1272 & $1976-1984$ & 50 \\
$1928 / 29$ & 1170 & $1976-1986$ & 48 \\
$1930 / 31$ & 1054 & $1976-1988$ & 46 \\
$1932 / 33$ & 1013 & $1976-1990$ & 44 \\
$1934 / 35$ & 877 & $1976-1992$ & 42 \\
$1936 / 37$ & 1052 & $1976-1992$ & 40 \\
$1938 / 39$ & 1275 & $1976-1992$ & 38 \\
$1940 / 41$ & 1364 & $1976-1992$ & 36 \\
$1942 / 43$ & 1547 & $1976-1992$ & 34 \\
$1944 / 45$ & 1662 & $1976-1992$ & 32 \\
$1946 / 47$ & 2034 & $1976-1992$ & 30 \\
$1948 / 49$ & 1918 & $1976-1992$ & 28 \\
$1950 / 51$ & 1870 & $1976-1992$ & 26 \\
$1952 / 53$ & 2129 & $1978-1992$ & 26 \\
$1954 / 55$ & 2326 & $1980-1992$ & 26 \\
$1956 / 57$ & 2500 & $1982-1992$ & 26 \\
$1958 / 59$ & 2774 & $1984-1992$ & 26 \\
$1960 / 61$ & 3049 & $1986-1992$ & 26 \\
\hline Total & 32,105 & & \\
\hline
\end{tabular}

Notes: Source- Revenue Canada T-4 Supplementary Tax File. Age is defined by the older of the birth cohorts in each two year cohort. 
Table 2: The Variance of Log Earnings in Various Samples

\begin{tabular}{lccccccc}
\hline Year & $\begin{array}{c}\text { Analysis } \\
\text { Sample } \\
\text { Ages }\end{array}$ & Analysis Sample & \multicolumn{2}{c}{$\begin{array}{c}\text { Individuals with } \\
\text { Positive Earnings and } \\
\text { Analysis Sample Ages }\end{array}$} & $\begin{array}{c}\text { Individuals Aged 25-58 } \\
\text { with Positive Earnings }\end{array}$ \\
\hline & & $\mathrm{N}$ & $\operatorname{Var}(Y)$ & $\mathrm{N}$ & $\operatorname{Var}(Y)$ & $\mathrm{N}$ & $\mathrm{Var}(Y)$ \\
\hline 1976 & $25-52$ & 19327 & 0.270 & 36789 & 0.597 & 41654 & 0.601 \\
1977 & $26-53$ & 19327 & 0.268 & 36235 & 0.614 & 42190 & 0.630 \\
1978 & $25-54$ & 21456 & 0.290 & 39539 & 0.629 & 42808 & 0.630 \\
1979 & $26-55$ & 21456 & 0.254 & 39592 & 0.603 & 44117 & 0.616 \\
1980 & $25-56$ & 23782 & 0.291 & 43484 & 0.644 & 45051 & 0.646 \\
1981 & $26-57$ & 23782 & 0.285 & 43332 & 0.647 & 46211 & 0.658 \\
1982 & $25-58$ & 26282 & 0.382 & 46325 & 0.745 & 46325 & 0.745 \\
1983 & $26-57$ & 25063 & 0.391 & 44006 & 0.772 & 46899 & 0.791 \\
1984 & $25-58$ & 27837 & 0.407 & 47855 & 0.798 & 47855 & 0.798 \\
1985 & $26-57$ & 26565 & 0.370 & 46119 & 0.777 & 49195 & 0.790 \\
1986 & $25-58$ & 29614 & 0.407 & 50286 & 0.790 & 50286 & 0.790 \\
1987 & $26-57$ & 28444 & 0.363 & 48599 & 0.766 & 51576 & 0.781 \\
1988 & $27-58$ & 28444 & 0.348 & 48611 & 0.765 & 53080 & 0.784 \\
1989 & $28-57$ & 27390 & 0.336 & 47037 & 0.765 & 54577 & 0.785 \\
1990 & $29-58$ & 27390 & 0.353 & 46489 & 0.768 & 55231 & 0.790 \\
1991 & $30-57$ & 26377 & 0.412 & 43618 & 0.815 & 54720 & 0.857 \\
1992 & $31-58$ & 26377 & 0.457 & 42231 & 0.846 & 54038 & 0.889 \\
\hline
\end{tabular}

Notes: Source- Revenue Canada T-4 Supplementary Tax File. 
Table 3: The Autocovariances, $C_{b}$, of the Log Earnings Residuals for the 1926/27 and 1958/59 Birth Cohorts

\begin{tabular}{|c|c|c|c|c|c|c|c|c|c|}
\hline \multicolumn{10}{|c|}{ Cohort Born 1926/1927 } \\
\hline & 1976 & 1977 & 1978 & 1979 & 1980 & 1981 & 1982 & 1983 & 1984 \\
\hline 1976 & $\begin{array}{c}0.287 \\
(0.023)\end{array}$ & 0.827 & 0.740 & 0.693 & 0.642 & 0.642 & 0.584 & 0.559 & 0.520 \\
\hline 1977 & $\begin{array}{c}0.231 \\
(0.016)\end{array}$ & $\begin{array}{c}0.272 \\
(0.019)\end{array}$ & 0.813 & 0.747 & 0.695 & 0.689 & 0.641 & 0.598 & 0.566 \\
\hline 1978 & $\begin{array}{c}0.221 \\
(0.017)\end{array}$ & $\begin{array}{c}0.237 \\
(0.016)\end{array}$ & $\begin{array}{c}0.312 \\
(0.024)\end{array}$ & 0.803 & 0.720 & 0.692 & 0.673 & 0.637 & 0.594 \\
\hline 1979 & $\begin{array}{c}0.198 \\
(0.014)\end{array}$ & $\begin{array}{c}0.207 \\
(0.014)\end{array}$ & $\begin{array}{c}0.239 \\
(0.017)\end{array}$ & $\begin{array}{c}0.284 \\
(0.021)\end{array}$ & 0.839 & 0.782 & 0.726 & 0.689 & 0.630 \\
\hline 1980 & $\begin{array}{c}0.197 \\
(0.013)\end{array}$ & $\begin{array}{c}0.208 \\
(0.013)\end{array}$ & $\begin{array}{c}0.231 \\
(0.016)\end{array}$ & $\begin{array}{c}0.257 \\
(0.021)\end{array}$ & $\begin{array}{c}0.330 \\
(0.030)\end{array}$ & 0.833 & 0.760 & 0.698 & 0.643 \\
\hline 1981 & $\begin{array}{c}0.202 \\
(0.013)\end{array}$ & $\begin{array}{c}0.211 \\
(0.014)\end{array}$ & $\begin{array}{c}0.227 \\
(0.016)\end{array}$ & $\begin{array}{c}0.245 \\
(0.020)\end{array}$ & $\begin{array}{c}0.281 \\
(0.025)\end{array}$ & $\begin{array}{c}0.346 \\
(0.028)\end{array}$ & 0.804 & 0.732 & 0.659 \\
\hline 1982 & $\begin{array}{c}0.209 \\
(0.016)\end{array}$ & $\begin{array}{c}0.223 \\
(0.016)\end{array}$ & $\begin{array}{c}0.251 \\
(0.020)\end{array}$ & $\begin{array}{c}0.258 \\
(0.022)\end{array}$ & $\begin{array}{c}0.292 \\
(0.027)\end{array}$ & $\begin{array}{c}0.316 \\
(0.026)\end{array}$ & $\begin{array}{c}0.446 \\
(0.035)\end{array}$ & 0.806 & 0.723 \\
\hline 1983 & $\begin{array}{c}0.218 \\
(0.018)\end{array}$ & $\begin{array}{c}0.227 \\
(0.016)\end{array}$ & $\begin{array}{c}0.259 \\
(0.022)\end{array}$ & $\begin{array}{c}0.267 \\
(0.023)\end{array}$ & $\begin{array}{c}0.292 \\
(0.028)\end{array}$ & $\begin{array}{c}0.313 \\
(0.027)\end{array}$ & $\begin{array}{c}0.392 \\
(0.032)\end{array}$ & $\begin{array}{c}0.530 \\
(0.043)\end{array}$ & 0.829 \\
\hline 1984 & $\begin{array}{c}0.215 \\
(0.016)\end{array}$ & $\begin{array}{c}0.228 \\
(0.017) \\
\end{array}$ & $\begin{array}{c}0.256 \\
(0.021) \\
\end{array}$ & $\begin{array}{c}0.259 \\
(0.022) \\
\end{array}$ & $\begin{array}{c}0.285 \\
(0.027) \\
\end{array}$ & $\begin{array}{c}0.299 \\
(0.026) \\
\end{array}$ & $\begin{array}{c}0.373 \\
(0.031) \\
\end{array}$ & $\begin{array}{c}0.466 \\
(0.037) \\
\end{array}$ & $\begin{array}{c}0.596 \\
(0.045) \\
\end{array}$ \\
\hline \multicolumn{10}{|c|}{ Cohort Born 1958/1959 } \\
\hline & 1984 & 1985 & 1986 & 1987 & 1988 & 1989 & 1990 & 1991 & 1992 \\
\hline 1984 & $\begin{array}{c}0.526 \\
(0.022)\end{array}$ & 0.716 & 0.591 & 0.540 & 0.501 & 0.443 & 0.411 & 0.386 & 0.350 \\
\hline 1985 & $\begin{array}{c}0.353 \\
(0.015)\end{array}$ & $\begin{array}{c}0.462 \\
(0.021)\end{array}$ & 0.737 & 0.638 & 0.569 & 0.517 & 0.473 & 0.451 & 0.403 \\
\hline 1986 & $\begin{array}{c}0.283 \\
(0.013)\end{array}$ & $\begin{array}{c}0.331 \\
(0.014)\end{array}$ & $\begin{array}{c}0.435 \\
(0.021)\end{array}$ & 0.756 & 0.609 & 0.552 & 0.508 & 0.472 & 0.436 \\
\hline 1987 & $\begin{array}{c}0.226 \\
(0.011)\end{array}$ & $\begin{array}{l}(0.011) \\
(0.011)\end{array}$ & $\begin{array}{c}0.288 \\
(0.013)\end{array}$ & $\begin{array}{c}0.333 \\
(0.016)\end{array}$ & 0.760 & 0.660 & 0.598 & 0.559 & 0.509 \\
\hline 1988 & $\begin{array}{c}0.207 \\
(0.011)\end{array}$ & $\begin{array}{c}0.220 \\
(0.011)\end{array}$ & $\begin{array}{c}0.229 \\
(0.010)\end{array}$ & $\begin{array}{c}0.250 \\
(0.012)\end{array}$ & $\begin{array}{c}0.325 \\
(0.016)\end{array}$ & 0.753 & 0.627 & 0.578 & 0.526 \\
\hline 1989 & $\begin{array}{c}0.179 \\
(0.010)\end{array}$ & $\begin{array}{c}0.196 \\
(0.010)\end{array}$ & $\begin{array}{c}0.203 \\
(0.010)\end{array}$ & $\begin{array}{c}0.213 \\
(0.010)\end{array}$ & $\begin{array}{c}0.240 \\
(0.010)\end{array}$ & $\begin{array}{c}0.311 \\
(0.016)\end{array}$ & 0.763 & 0.670 & 0.593 \\
\hline 1990 & $\begin{array}{c}0.168 \\
(0.010)\end{array}$ & $\begin{array}{c}0.181 \\
(0.010)\end{array}$ & $\begin{array}{l}(0.010) \\
(0.010)\end{array}$ & $\begin{array}{c}0.195 \\
(0.010)\end{array}$ & $\begin{array}{l}(0.201) \\
(0.009)\end{array}$ & $\begin{array}{c}0.240 \\
(0.012)\end{array}$ & $\begin{array}{c}0.318 \\
(0.016)\end{array}$ & 0.738 & 0.631 \\
\hline 1991 & $\begin{array}{c}0.180 \\
(0.011)\end{array}$ & $\begin{array}{c}0.197 \\
(0.011)\end{array}$ & $\begin{array}{c}0.200 \\
(0.011)\end{array}$ & $\begin{array}{c}0.207 \\
(0.012)\end{array}$ & $\begin{array}{c}0.211 \\
(0.011)\end{array}$ & $\begin{array}{c}0.240 \\
(0.012)\end{array}$ & $\begin{array}{c}0.267 \\
(0.012)\end{array}$ & $\begin{array}{c}0.412 \\
(0.021)\end{array}$ & 0.735 \\
\hline 1992 & $\begin{array}{c}0.174 \\
(0.011)\end{array}$ & $\begin{array}{c}0.188 \\
(0.011)\end{array}$ & $\begin{array}{c}0.197 \\
(0.011)\end{array}$ & $\begin{array}{c}0.202 \\
(0.011)\end{array}$ & $\begin{array}{c}0.206 \\
(0.011)\end{array}$ & $\begin{array}{c}0.227 \\
(0.011)\end{array}$ & $\begin{array}{c}0.244 \\
(0.011)\end{array}$ & $\begin{array}{c}0.324 \\
(0.015)\end{array}$ & $\begin{array}{c}0.471 \\
(0.024)\end{array}$ \\
\hline
\end{tabular}

Notes: Source- Revenue Canada T-4 Supplementary Tax File. Standard error estimates are in parentheses. Correlation coefficients are reported above the diagonal. 
Table 4: The Autocovariances, $C_{b}$, of the Log Earnings Residuals for the 1942/43 Birth Cohort

\begin{tabular}{|c|c|c|c|c|c|c|c|c|c|}
\hline & 1976 & 1977 & 1978 & 1979 & 1980 & 1981 & 1982 & 1983 & 1984 \\
\hline 1976 & $\begin{array}{c}0.225 \\
(0.017)\end{array}$ & 0.807 & 0.675 & 0.633 & 0.636 & 0.577 & 0.572 & 0.528 & 0.547 \\
\hline 1977 & $\begin{array}{c}0.178 \\
(0.013)\end{array}$ & $\begin{array}{c}0.216 \\
(0.019)\end{array}$ & 0.783 & 0.694 & 0.695 & 0.633 & 0.623 & 0.560 & 0.578 \\
\hline 1978 & $\begin{array}{c}0.157 \\
(0.010)\end{array}$ & $\begin{array}{c}0.178 \\
(0.012)\end{array}$ & $\begin{array}{c}0.241 \\
(0.018)\end{array}$ & 0.779 & 0.732 & 0.665 & 0.648 & 0.609 & 0.619 \\
\hline 1979 & $\begin{array}{c}0.148 \\
(0.011)\end{array}$ & $\begin{array}{c}0.159 \\
(0.011)\end{array}$ & $\begin{array}{c}0.188 \\
(0.012)\end{array}$ & $\begin{array}{c}0.242 \\
(0.021)\end{array}$ & 0.772 & 0.674 & 0.640 & 0.586 & 0.580 \\
\hline 1980 & $\begin{array}{c}0.145 \\
(0.010)\end{array}$ & $\begin{array}{c}0.155 \\
(0.010)\end{array}$ & $\begin{array}{c}0.173 \\
(0.012)\end{array}$ & $\begin{array}{c}0.183 \\
(0.012)\end{array}$ & $\begin{array}{c}0.231 \\
(0.017)\end{array}$ & 0.794 & 0.700 & 0.652 & 0.628 \\
\hline 1981 & $\begin{array}{c}0.140 \\
(0.009)\end{array}$ & $\begin{array}{c}0.150 \\
(0.010)\end{array}$ & $\begin{array}{c}0.167 \\
(0.010)\end{array}$ & $\begin{array}{c}0.169 \\
(0.011)\end{array}$ & $\begin{array}{c}0.195 \\
(0.014)\end{array}$ & $\begin{array}{c}0.261 \\
(0.022)\end{array}$ & 0.757 & 0.674 & 0.646 \\
\hline 1982 & $\begin{array}{c}0.156 \\
(0.010)\end{array}$ & $\begin{array}{c}0.166 \\
(0.013)\end{array}$ & $\begin{array}{c}0.182 \\
(0.012)\end{array}$ & $\begin{array}{c}0.180 \\
(0.011)\end{array}$ & $\begin{array}{c}0.193 \\
(0.012)\end{array}$ & $\begin{array}{c}0.221 \\
(0.016)\end{array}$ & $\begin{array}{c}0.328 \\
(0.025)\end{array}$ & 0.778 & 0.699 \\
\hline 1983 & $\begin{array}{c}0.149 \\
(0.011)\end{array}$ & $\begin{array}{c}0.154 \\
(0.010)\end{array}$ & $\begin{array}{c}0.177 \\
(0.013)\end{array}$ & $\begin{array}{c}0.171 \\
(0.012)\end{array}$ & $\begin{array}{c}0.186 \\
(0.012)\end{array}$ & $\begin{array}{c}0.204 \\
(0.015)\end{array}$ & $\begin{array}{c}0.264 \\
(0.017)\end{array}$ & $\begin{array}{c}0.351 \\
(0.026)\end{array}$ & 0.781 \\
\hline 1984 & $\begin{array}{c}0.151 \\
(0.012)\end{array}$ & $\begin{array}{c}0.156 \\
(0.011)\end{array}$ & $\begin{array}{c}0.176 \\
(0.013)\end{array}$ & $\begin{array}{c}0.166 \\
(0.011)\end{array}$ & $\begin{array}{c}0.175 \\
(0.012)\end{array}$ & $\begin{array}{c}0.192 \\
(0.013)\end{array}$ & $\begin{array}{c}0.233 \\
(0.015)\end{array}$ & $\begin{array}{c}0.269 \\
(0.019)\end{array}$ & $\begin{array}{r}0.338 \\
(0.027)\end{array}$ \\
\hline 1985 & $\begin{array}{c}0.146 \\
(0.009)\end{array}$ & $\begin{array}{c}0.147 \\
(0.010)\end{array}$ & $\begin{array}{c}0.169 \\
(0.012)\end{array}$ & $\begin{array}{c}0.169 \\
(0.012)\end{array}$ & $\begin{array}{c}0.177 \\
(0.012)\end{array}$ & $\begin{array}{c}0.185 \\
(0.012)\end{array}$ & $\begin{array}{c}0.221 \\
(0.013)\end{array}$ & $\begin{array}{c}0.238 \\
(0.014)\end{array}$ & $\begin{array}{c}0.253 \\
(0.016)\end{array}$ \\
\hline 1986 & $\begin{array}{c}0.140 \\
(0.009)\end{array}$ & $\begin{array}{c}0.140 \\
(0.009)\end{array}$ & $\begin{array}{c}0.160 \\
(0.010)\end{array}$ & $\begin{array}{c}0.159 \\
(0.011)\end{array}$ & $\begin{array}{c}0.166 \\
(0.011)\end{array}$ & $\begin{array}{c}0.177 \\
(0.011)\end{array}$ & $\begin{array}{c}0.209 \\
(0.013)\end{array}$ & $\begin{array}{c}0.218 \\
(0.013)\end{array}$ & $\begin{array}{c}0.227 \\
(0.014)\end{array}$ \\
\hline 1987 & $\begin{array}{c}0.139 \\
(0.009)\end{array}$ & $\begin{array}{c}0.146 \\
(0.010)\end{array}$ & $\begin{array}{c}0.165 \\
(0.012)\end{array}$ & $\begin{array}{c}0.160 \\
(0.011)\end{array}$ & $\begin{array}{c}0.165 \\
(0.012)\end{array}$ & $\begin{array}{c}0.174 \\
(0.011)\end{array}$ & $\begin{array}{c}0.203 \\
(0.013)\end{array}$ & $\begin{array}{c}0.213 \\
(0.015)\end{array}$ & $\begin{array}{c}0.224 \\
(0.015)\end{array}$ \\
\hline 1988 & $\begin{array}{c}0.137 \\
(0.009)\end{array}$ & $\begin{array}{c}0.142 \\
(0.010)\end{array}$ & $\begin{array}{c}0.160 \\
(0.011)\end{array}$ & $\begin{array}{c}0.159 \\
(0.011)\end{array}$ & $\begin{array}{c}0.167 \\
(0.012)\end{array}$ & $\begin{array}{c}0.173 \\
(0.012)\end{array}$ & $\begin{array}{c}0.200 \\
(0.013)\end{array}$ & $\begin{array}{c}0.201 \\
(0.013)\end{array}$ & $\begin{array}{c}0.213 \\
(0.014)\end{array}$ \\
\hline 1989 & $\begin{array}{c}0.135 \\
(0.009)\end{array}$ & $\begin{array}{c}0.139 \\
(0.010)\end{array}$ & $\begin{array}{c}0.155 \\
(0.011)\end{array}$ & $\begin{array}{c}0.154 \\
(0.011)\end{array}$ & $\begin{array}{c}0.159 \\
(0.011)\end{array}$ & $\begin{array}{c}0.172 \\
(0.013)\end{array}$ & $\begin{array}{c}0.201 \\
(0.013)\end{array}$ & $\begin{array}{c}0.203 \\
(0.014)\end{array}$ & $\begin{array}{r}0.208 \\
(0.014)\end{array}$ \\
\hline 1990 & $\begin{array}{c}0.132 \\
(0.010)\end{array}$ & $\begin{array}{c}0.133 \\
(0.010)\end{array}$ & $\begin{array}{c}0.150 \\
(0.011)\end{array}$ & $\begin{array}{c}0.149 \\
(0.012)\end{array}$ & $\begin{array}{c}0.151 \\
(0.011)\end{array}$ & $\begin{array}{c}0.161 \\
(0.011)\end{array}$ & $\begin{array}{c}0.194 \\
(0.013)\end{array}$ & $\begin{array}{c}0.199 \\
(0.014)\end{array}$ & $\begin{array}{c}0.203 \\
(0.014)\end{array}$ \\
\hline 1991 & $\begin{array}{c}0.129 \\
(0.009)\end{array}$ & $\begin{array}{c}0.136 \\
(0.010)\end{array}$ & $\begin{array}{c}0.148 \\
(0.010)\end{array}$ & $\begin{array}{c}0.151 \\
(0.011)\end{array}$ & $\begin{array}{c}0.153 \\
(0.010)\end{array}$ & $\begin{array}{c}0.165 \\
(0.011)\end{array}$ & $\begin{array}{c}0.211 \\
(0.014)\end{array}$ & $\begin{array}{c}0.201 \\
(0.013)\end{array}$ & $\begin{array}{c}0.208 \\
(0.013)\end{array}$ \\
\hline 1992 & $\begin{array}{c}0.135 \\
(0.009)\end{array}$ & $\begin{array}{c}0.136 \\
(0.010)\end{array}$ & $\begin{array}{c}0.153 \\
(0.011)\end{array}$ & $\begin{array}{c}0.147 \\
(0.010)\end{array}$ & $\begin{array}{c}0.155 \\
(0.011)\end{array}$ & $\begin{array}{c}0.168 \\
(0.011)\end{array}$ & $\begin{array}{c}0.216 \\
(0.015)\end{array}$ & $\begin{array}{c}0.209 \\
(0.015)\end{array}$ & $\begin{array}{c}0.211 \\
(0.013)\end{array}$ \\
\hline
\end{tabular}

Notes: Source- Revenue Canada T-4 Supplementary Tax File. Standard error estimates are in parentheses. Correlation coefficients are reported above the diagonal. 
Table 4: (cont.)

\begin{tabular}{|c|c|c|c|c|c|c|c|c|}
\hline & 1985 & 1986 & 1987 & 1988 & 1989 & 1990 & 1991 & 1992 \\
\hline 1976 & 0.577 & 0.568 & 0.549 & 0.517 & 0.516 & 0.494 & 0.464 & 0.433 \\
\hline 1977 & 0.596 & 0.578 & 0.590 & 0.547 & 0.540 & 0.510 & 0.497 & 0.446 \\
\hline 1978 & 0.647 & 0.628 & 0.632 & 0.584 & 0.571 & 0.546 & 0.512 & 0.473 \\
\hline 1979 & 0.647 & 0.623 & 0.610 & 0.580 & 0.568 & 0.541 & 0.523 & 0.455 \\
\hline 1980 & 0.690 & 0.663 & 0.644 & 0.623 & 0.598 & 0.560 & 0.540 & 0.490 \\
\hline 1981 & 0.681 & 0.667 & 0.641 & 0.607 & 0.610 & 0.563 & 0.552 & 0.501 \\
\hline 1982 & 0.726 & 0.702 & 0.666 & 0.625 & 0.635 & 0.604 & 0.627 & 0.573 \\
\hline 1983 & 0.755 & 0.708 & 0.674 & 0.608 & 0.618 & 0.599 & 0.576 & 0.537 \\
\hline 1984 & 0.818 & 0.752 & 0.725 & 0.657 & 0.646 & 0.623 & 0.610 & 0.552 \\
\hline 1985 & $\begin{array}{c}0.283 \\
(0.020)\end{array}$ & 0.848 & 0.793 & 0.723 & 0.717 & 0.676 & 0.637 & 0.598 \\
\hline 1986 & $\begin{array}{c}0.235 \\
(0.014)\end{array}$ & $\begin{array}{c}0.271 \\
(0.017)\end{array}$ & 0.851 & 0.749 & 0.755 & 0.709 & 0.669 & 0.597 \\
\hline 1987 & $\begin{array}{c}0.225 \\
(0.015)\end{array}$ & $\begin{array}{c}0.236 \\
(0.015)\end{array}$ & $\begin{array}{c}0.284 \\
(0.020)\end{array}$ & 0.827 & 0.766 & 0.712 & 0.690 & 0.612 \\
\hline 1988 & $\begin{array}{c}0.215 \\
(0.014)\end{array}$ & $\begin{array}{c}0.218 \\
(0.014)\end{array}$ & $\begin{array}{c}0.246 \\
(0.017)\end{array}$ & $\begin{array}{c}0.312 \\
(0.025)\end{array}$ & 0.825 & 0.752 & 0.701 & 0.632 \\
\hline 1989 & $\begin{array}{c}0.211 \\
(0.014)\end{array}$ & $\begin{array}{c}0.217 \\
(0.014)\end{array}$ & $\begin{array}{c}0.226 \\
(0.015)\end{array}$ & $\begin{array}{c}0.255 \\
(0.018)\end{array}$ & $\begin{array}{c}0.306 \\
(0.024)\end{array}$ & 0.831 & 0.739 & 0.668 \\
\hline 1990 & $\begin{array}{c}0.202 \\
(0.014)\end{array}$ & $\begin{array}{c}0.207 \\
(0.014)\end{array}$ & $\begin{array}{c}0.213 \\
(0.015)\end{array}$ & $\begin{array}{c}0.236 \\
(0.016)\end{array}$ & $\begin{array}{c}0.258 \\
(0.017)\end{array}$ & $\begin{array}{c}0.315 \\
(0.021)\end{array}$ & 0.799 & 0.697 \\
\hline 1991 & $\begin{array}{c}0.199 \\
(0.012)\end{array}$ & $\begin{array}{c}0.205 \\
(0.013)\end{array}$ & $\begin{array}{c}0.216 \\
(0.015)\end{array}$ & $\begin{array}{c}0.230 \\
(0.015)\end{array}$ & $\begin{array}{c}0.240 \\
(0.015)\end{array}$ & $\begin{array}{c}0.263 \\
(0.017)\end{array}$ & $\begin{array}{c}0.345 \\
(0.024)\end{array}$ & 0.789 \\
\hline 1992 & $\begin{array}{c}0.209 \\
(0.014)\end{array}$ & $\begin{array}{c}0.204 \\
(0.013)\end{array}$ & $\begin{array}{c}0.214 \\
(0.014)\end{array}$ & $\begin{array}{c}0.232 \\
(0.015)\end{array}$ & $\begin{array}{c}0.243 \\
(0.015)\end{array}$ & $\begin{array}{c}0.257 \\
(0.017)\end{array}$ & $\begin{array}{c}0.305 \\
(0.019)\end{array}$ & $\begin{array}{c}0.433 \\
(0.033)\end{array}$ \\
\hline
\end{tabular}


Table 5: Estimates of Earnings Dynamics Models

\begin{tabular}{|c|c|c|c|c|c|c|}
\hline & \multicolumn{2}{|c|}{ Base Model } & \multicolumn{2}{|c|}{ Extended Model 1} & \multicolumn{2}{|c|}{ Extended Model 2} \\
\hline & Estimate & $\begin{array}{c}\text { Standard } \\
\text { Error }\end{array}$ & Estimate & $\begin{array}{c}\text { Standard } \\
\text { Error }\end{array}$ & Estimate & $\begin{array}{c}\text { Standard } \\
\text { Error }\end{array}$ \\
\hline \multicolumn{7}{|c|}{ Persistent Component } \\
\hline$\overline{\sigma_{\alpha}^{2}}$ & 0.134 & 0.007 & 0.123 & 0.008 & & \\
\hline$\sigma_{\beta}^{2}$ & 0.00009 & 0.00003 & 0.00002 & 0.00025 & 0.00030 & 0.00009 \\
\hline$\sigma_{\alpha \beta}$ & -0.0031 & 0.0004 & -0.0017 & 0.0007 & -0.0031 & 0.0009 \\
\hline$\sigma_{\psi}^{2}$ & & & $-4.68 \mathrm{E}-08$ & $2.04 \mathrm{E}-07$ & $3.00 \mathrm{E}-07$ & $7.38 \mathrm{E}-08$ \\
\hline$\sigma_{\alpha \psi}$ & & & $-4.07 \mathrm{E}-05$ & $1.67 \mathrm{E}-05$ & $-1.64 \mathrm{E}-05$ & $7.19 \mathrm{E}-06$ \\
\hline$\sigma_{\beta \psi}$ & & & $2.24 \mathrm{E}-06$ & $6.09 \mathrm{E}-06$ & $-8.52 \mathrm{E}-06$ & $2.11 \mathrm{E}-06$ \\
\hline$\sigma_{r}^{2}$ & 0.007 & 0.001 & 0.006 & 0.001 & 0.004 & 0.001 \\
\hline$p_{76}$ & 1.000 & & 1.000 & & 1.000 & \\
\hline$p_{77}$ & 1.035 & 0.012 & 1.035 & 0.012 & 1.046 & 0.017 \\
\hline$p_{78}$ & 1.028 & 0.015 & 1.029 & 0.015 & 1.066 & 0.027 \\
\hline$p_{79}$ & 1.005 & 0.015 & 1.007 & 0.015 & 1.066 & 0.035 \\
\hline$p_{80}$ & 1.030 & 0.017 & 1.032 & 0.017 & 1.115 & 0.047 \\
\hline$p_{81}$ & 1.050 & 0.018 & 1.055 & 0.019 & 1.155 & 0.058 \\
\hline$p_{82}$ & 1.143 & 0.020 & 1.151 & 0.022 & 1.281 & 0.075 \\
\hline$p_{83}$ & 1.124 & 0.022 & 1.128 & 0.023 & 1.309 & 0.088 \\
\hline$p_{84}$ & 1.125 & 0.022 & 1.114 & 0.023 & 1.325 & 0.103 \\
\hline$p_{85}$ & 1.122 & 0.022 & 1.127 & 0.023 & 1.374 & 0.123 \\
\hline$p_{86}$ & 1.111 & 0.022 & 1.115 & 0.023 & 1.381 & 0.139 \\
\hline$p_{87}$ & 1.098 & 0.023 & 1.101 & 0.024 & 1.403 & 0.158 \\
\hline$p_{88}$ & 1.105 & 0.024 & 1.108 & 0.024 & 1.440 & 0.181 \\
\hline$p_{89}$ & 1.126 & 0.025 & 1.129 & 0.025 & 1.498 & 0.208 \\
\hline$p_{90}$ & 1.127 & 0.024 & 1.130 & 0.025 & 1.532 & 0.236 \\
\hline$p_{91}$ & 1.234 & 0.026 & 1.238 & 0.027 & 1.665 & 0.284 \\
\hline$p_{92}$ & 1.253 & 0.027 & 1.256 & 0.028 & 1.726 & 0.324 \\
\hline$\sigma_{\alpha(24 / 25)}^{2}$ & & & & & 0.266 & 0.050 \\
\hline$\sigma_{\alpha(26 / 28)}^{2}$ & & & & & 0.245 & 0.045 \\
\hline$\sigma_{\alpha(28 / 29)}^{2}$ & & & & & 0.227 & 0.040 \\
\hline$\sigma_{\alpha(30 / 31)}^{2}$ & & & & & 0.203 & 0.036 \\
\hline
\end{tabular}

Notes: Source -- Revenue Canada T-4 Supplementary Tax File. 
Table 5: (cont.)

\begin{tabular}{|c|c|c|c|c|c|c|}
\hline & \multicolumn{2}{|c|}{ Base Model } & \multicolumn{2}{|c|}{ Extended Model 1} & \multicolumn{2}{|c|}{ Extended Model 2} \\
\hline & Estimate & $\begin{array}{l}\text { Standard } \\
\text { Error }\end{array}$ & Estimate & $\begin{array}{l}\text { Standard } \\
\text { Error }\end{array}$ & Estimate & $\begin{array}{c}\text { Standard } \\
\text { Error }\end{array}$ \\
\hline \multicolumn{7}{|c|}{ Persistent Component } \\
\hline$\sigma_{\alpha(32 / 33)}^{2}$ & & & & & 0.171 & 0.035 \\
\hline$\sigma_{\alpha(34 / 35)}^{2}$ & & & & & 0.201 & 0.028 \\
\hline$\sigma_{\alpha(36 / 37)}^{2}$ & & & & & 0.177 & 0.025 \\
\hline$\sigma_{\alpha(38 / 39)}^{2}$ & & & & & 0.157 & 0.023 \\
\hline$\sigma_{\alpha(40 / 41)}^{2}$ & & & & & 0.147 & 0.020 \\
\hline$\sigma_{\alpha(42 / 43)}^{2}$ & & & & & 0.142 & 0.016 \\
\hline$\sigma_{\alpha(44 / 45)}^{2}$ & & & & & 0.137 & 0.013 \\
\hline$\sigma_{\alpha(46 / 47)}^{2}$ & & & & & 0.121 & 0.011 \\
\hline$\sigma_{\alpha(48 / 49)}^{2}$ & & & & & 0.110 & 0.009 \\
\hline$\sigma_{\alpha(50 / 51)}^{2}$ & & & & & 0.113 & 0.007 \\
\hline$\sigma_{\alpha(52 / 53)}^{2}$ & & & & & 0.108 & 0.007 \\
\hline$\sigma_{\alpha(54 / 55)}^{2}$ & & & & & 0.107 & 0.009 \\
\hline$\sigma_{\alpha(56 / 57)}^{2}$ & & & & & 0.104 & 0.012 \\
\hline$\sigma_{\alpha(58 / 59)}^{2}$ & & & & & 0.101 & 0.015 \\
\hline$\sigma_{\alpha(60 / 61)}^{2}$ & & & & & 0.106 & 0.021 \\
\hline \multicolumn{7}{|c|}{ Transitory Component } \\
\hline$\sigma_{24 / 25}^{2}$ & 0.133 & 0.038 & 0.139 & 0.039 & 0.108 & 0.020 \\
\hline$\sigma_{26 / 28}^{2}$ & 0.084 & 0.031 & 0.088 & 0.032 & 0.076 & 0.025 \\
\hline$\sigma_{28 / 29}^{2}$ & 0.116 & 0.033 & 0.120 & 0.033 & 0.112 & 0.023 \\
\hline$\sigma_{30 / 31}^{2}$ & 0.071 & 0.029 & 0.075 & 0.030 & 0.084 & 0.023 \\
\hline$\sigma_{32 / 33}^{2}$ & 0.071 & 0.027 & 0.075 & 0.024 & 0.119 & 0.021 \\
\hline$\sigma_{34 / 35}^{2}$ & 0.127 & 0.040 & 0.131 & 0.040 & 0.092 & 0.022 \\
\hline$\sigma_{36 / 37}^{2}$ & 0.085 & 0.029 & 0.088 & 0.030 & 0.077 & 0.024 \\
\hline$\sigma_{38 / 39}^{2}$ & 0.044 & 0.025 & 0.046 & 0.026 & 0.061 & 0.018 \\
\hline$\sigma_{40 / 41}^{2}$ & 0.066 & 0.025 & 0.068 & 0.026 & 0.086 & 0.019 \\
\hline$\sigma_{42 / 43}^{2}$ & 0.074 & 0.023 & 0.076 & 0.024 & 0.094 & 0.020 \\
\hline$\sigma_{44 / 45}^{2}$ & 0.054 & 0.025 & 0.057 & 0.026 & 0.075 & 0.019 \\
\hline$\sigma_{46 / 47}^{2}$ & 0.071 & 0.021 & 0.075 & 0.021 & 0.116 & 0.019 \\
\hline$\sigma_{48 / 49}^{2}$ & 0.090 & 0.022 & 0.097 & 0.022 & 0.147 & 0.019 \\
\hline$\sigma_{50 / 51}^{2}$ & 0.167 & 0.024 & 0.178 & 0.024 & 0.206 & 0.022 \\
\hline
\end{tabular}


Table 5: (cont.)

\begin{tabular}{|c|c|c|c|c|c|c|}
\hline & \multicolumn{2}{|c|}{ Base Model } & \multicolumn{2}{|c|}{ Extended Model 1} & \multicolumn{2}{|c|}{ Extended Model 2} \\
\hline & Estimate & $\begin{array}{c}\text { Standard } \\
\text { Error }\end{array}$ & Estimate & $\begin{array}{l}\text { Standard } \\
\text { Error }\end{array}$ & Estimate & $\begin{array}{l}\text { Standard } \\
\text { Error }\end{array}$ \\
\hline \multicolumn{7}{|c|}{ Persistent Component } \\
\hline$\sigma_{52 / 53}^{2}$ & 0.157 & 0.024 & 0.168 & 0.028 & 0.194 & 0.022 \\
\hline$\sigma_{54 / 55}^{2}$ & 0.251 & 0.026 & 0.262 & 0.026 & 0.271 & 0.024 \\
\hline$\sigma_{56 / 57}^{2}$ & 0.295 & 0.026 & 0.309 & 0.026 & 0.301 & 0.023 \\
\hline$\sigma_{58 / 59}^{2}$ & 0.377 & 0.026 & 0.394 & 0.027 & 0.367 & 0.023 \\
\hline$\sigma_{60 / 61}^{2}$ & 0.388 & 0.025 & 0.400 & 0.025 & 0.332 & 0.021 \\
\hline$\rho$ & 0.540 & 0.011 & 0.556 & 0.012 & 0.476 & 0.010 \\
\hline$\gamma_{0}$ & 0.090 & 0.011 & 0.095 & 0.010 & 0.159 & 0.012 \\
\hline$\gamma_{1}$ & -0.005 & 0.002 & -0.006 & 0.001 & -0.023 & 0.003 \\
\hline$\gamma_{2}$ & 0.0001 & 0.0001 & 0.0001 & 0.0001 & 0.0020 & 0.0004 \\
\hline$\gamma_{3}$ & $2.21 \mathrm{E}-06$ & $2.49 \mathrm{E}-06$ & $5.06 \mathrm{E}-07$ & $1.75 \mathrm{E}-06$ & $-7.98 \mathrm{E}-05$ & $1.81 \mathrm{E}-05$ \\
\hline$\gamma_{4}$ & $2.10 \mathrm{E}-09$ & $1.43 \mathrm{E}-08$ & $3.10 \mathrm{E}-09$ & $1.44 \mathrm{E}-08$ & $1.17 \mathrm{E}-06$ & $2.79 \mathrm{E}-07$ \\
\hline$\lambda_{77}$ & 1.000 & & 1.000 & & 1.000 & \\
\hline$\lambda_{78}$ & 1.132 & 0.060 & 1.122 & 0.058 & 1.067 & 0.042 \\
\hline$\lambda_{79}$ & 0.950 & 0.051 & 0.944 & 0.049 & 0.909 & 0.037 \\
\hline$\lambda_{80}$ & 1.060 & 0.061 & 1.052 & 0.058 & 0.991 & 0.041 \\
\hline$\lambda_{81}$ & 1.066 & 0.062 & 1.052 & 0.060 & 0.974 & 0.041 \\
\hline$\lambda_{82}$ & 1.397 & 0.079 & 1.381 & 0.077 & 1.236 & 0.049 \\
\hline$\lambda_{83}$ & 1.527 & 0.085 & 1.503 & 0.079 & 1.316 & 0.050 \\
\hline$\lambda_{84}$ & 1.379 & 0.080 & 1.357 & 0.076 & 1.211 & 0.048 \\
\hline$\lambda_{85}$ & 1.343 & 0.077 & 1.318 & 0.071 & 1.138 & 0.046 \\
\hline$\lambda_{86}$ & 1.339 & 0.078 & 1.320 & 0.074 & 1.152 & 0.046 \\
\hline$\lambda_{87}$ & 1.304 & 0.076 & 1.287 & 0.072 & 1.070 & 0.044 \\
\hline$\lambda_{88}$ & 1.285 & 0.074 & 1.273 & 0.071 & 1.042 & 0.045 \\
\hline$\lambda_{89}$ & 1.260 & 0.076 & 1.249 & 0.073 & 1.003 & 0.047 \\
\hline$\lambda_{90}$ & 1.405 & 0.080 & 1.394 & 0.077 & 1.122 & 0.054 \\
\hline$\lambda_{91}$ & 1.513 & 0.087 & 1.498 & 0.083 & 1.271 & 0.066 \\
\hline$\lambda_{92}$ & 1.715 & 0.097 & 1.709 & 0.093 & 1.414 & 0.073 \\
\hline
\end{tabular}


Table 6: Trend and Cyclical Variation of the Persistent and Transitory Components, Various Models

\begin{tabular}{|c|c|c|c|c|c|}
\hline & Constant & $\begin{array}{l}\text { Unemployment } \\
\text { Rate }\end{array}$ & Linear Trend & $\overline{\mathrm{R}^{2}}$ & Durbin-Watson \\
\hline \multicolumn{6}{|c|}{ Persistent Component } \\
\hline Base Model & $\begin{array}{c}0.0970 \\
(0.0117)\end{array}$ & $\begin{array}{c}0.0068 \\
(0.0014)\end{array}$ & $\begin{array}{c}0.0034 \\
(0.0004)\end{array}$ & 0.904 & 1.065 \\
\hline $\begin{array}{l}\text { Restricted } \\
\text { Model } 1\end{array}$ & $\begin{array}{c}0.0582 \\
(0.0082)\end{array}$ & $\begin{array}{c}0.0076 \\
(0.0010)\end{array}$ & $\begin{array}{c}0.0025 \\
(0.0003)\end{array}$ & 0.927 & 1.535 \\
\hline $\begin{array}{l}\text { Restricted } \\
\text { Model } 2\end{array}$ & $\begin{array}{c}0.0764 \\
(0.0119)\end{array}$ & $\begin{array}{c}0.0072 \\
(0.0014)\end{array}$ & $\begin{array}{c}0.0024 \\
(0.0004)\end{array}$ & 0.862 & 1.028 \\
\hline $\begin{array}{l}\text { Restricted } \\
\text { Model } 3\end{array}$ & $\begin{array}{c}0.0551 \\
(0.0072)\end{array}$ & $\begin{array}{c}0.0077 \\
(0.0008)\end{array}$ & $\begin{array}{c}0.0030 \\
(0.0003)\end{array}$ & 0.957 & 1.882 \\
\hline $\begin{array}{l}\text { Extended } \\
\text { Model } 2\end{array}$ & $\begin{array}{c}0.0748 \\
(0.0161)\end{array}$ & $\begin{array}{c}0.0088 \\
(0.0019)\end{array}$ & $\begin{array}{c}0.0045 \\
(0.0006)\end{array}$ & 0.878 & 1.202 \\
\hline \multicolumn{6}{|c|}{ Transitory Component } \\
\hline Base Model & $\begin{array}{c}-0.0089 \\
(0.0159)\end{array}$ & $\begin{array}{l}0.0081 \\
(0.018)\end{array}$ & $\begin{array}{c}0.0025 \\
(0.0006)\end{array}$ & 0.804 & 1.044 \\
\hline $\begin{array}{l}\text { Restricted } \\
\text { Model } 1\end{array}$ & $\begin{array}{c}0.0367 \\
(0.0282)\end{array}$ & $\begin{array}{c}0.0064 \\
(0.0033)\end{array}$ & $\begin{array}{c}0.0035 \\
(0.0011)\end{array}$ & 0.608 & 0.521 \\
\hline $\begin{array}{l}\text { Restricted } \\
\text { Model } 2\end{array}$ & $\begin{array}{c}0.0021 \\
(0.0113)\end{array}$ & $\begin{array}{c}0.0090 \\
(0.0013)\end{array}$ & $\begin{array}{c}0.0051 \\
(0.0004)\end{array}$ & 0.954 & 1.768 \\
\hline $\begin{array}{l}\text { Restricted } \\
\text { Model } 3\end{array}$ & $\begin{array}{c}0.0495 \\
(0.0204)\end{array}$ & $\begin{array}{c}0.0067 \\
(0.0024)\end{array}$ & $\begin{array}{c}0.0032 \\
(0.0008)\end{array}$ & 0.738 & 0.721 \\
\hline $\begin{array}{l}\text { Extended } \\
\text { Model } 2\end{array}$ & $\begin{array}{l}-0.0150 \\
(0.0097)\end{array}$ & $\begin{array}{c}0.0109 \\
(0.0011)\end{array}$ & $\begin{array}{c}0.0012 \\
(0.0004)\end{array}$ & 0.913 & 1.258 \\
\hline
\end{tabular}

Notes: The coefficient estimates come from ordinary least squares estimation of regressions in which the dependent variable is the estimated persistent or transitory component (for a male aged 40 ) from the indicated model and the explanatory variables are the unemployment rate and a linear time trend variable. The sample period is 1976$1992(\mathrm{~T}=17)$. 
Table 7: Further Estimates of Earnings Dynamics Models

\begin{tabular}{|c|c|c|c|c|c|c|}
\hline & \multicolumn{2}{|c|}{ Restricted Model 1} & \multicolumn{2}{|c|}{ Restricted Model 2} & \multicolumn{2}{|c|}{ Restricted Model 3} \\
\hline & Estimate & $\begin{array}{c}\text { Standard } \\
\text { Error }\end{array}$ & Estimate & $\begin{array}{c}\text { Standard } \\
\text { Error }\end{array}$ & Estimate & $\begin{array}{c}\text { Standard } \\
\text { Error }\end{array}$ \\
\hline \multicolumn{7}{|c|}{ Persistent Component } \\
\hline$\sigma_{\alpha}^{2}$ & 0.084 & 0.008 & 0.095 & 0.004 & 0.126 & 0.008 \\
\hline$\sigma_{\beta}^{2}$ & 0.00006 & 0.00003 & & & 0.00017 & 0.00003 \\
\hline$\sigma_{\alpha \beta}$ & 0.0005 & 0.0005 & & & -0.0015 & 0.0005 \\
\hline$\sigma_{r}^{2}$ & & & 0.0032 & 0.0004 & & \\
\hline$p_{76}$ & 1.000 & & 1.000 & & 1.000 & \\
\hline$p_{77}$ & 1.049 & 0.013 & 1.023 & 0.013 & 1.031 & 0.012 \\
\hline$p_{78}$ & 1.056 & 0.017 & 1.010 & 0.017 & 1.018 & 0.015 \\
\hline$p_{79}$ & 1.048 & 0.017 & 0.986 & 0.018 & 1.008 & 0.016 \\
\hline$p_{80}$ & 1.089 & 0.020 & 1.013 & 0.021 & 1.041 & 0.018 \\
\hline$p_{81}$ & 1.126 & 0.021 & 1.042 & 0.023 & 1.082 & 0.020 \\
\hline$p_{82}$ & 1.238 & 0.025 & 1.147 & 0.029 & 1.194 & 0.025 \\
\hline$p_{83}$ & 1.212 & 0.026 & 1.112 & 0.030 & 1.182 & 0.026 \\
\hline$p_{84}$ & 1.214 & 0.027 & 1.117 & 0.031 & 1.185 & 0.026 \\
\hline$p_{85}$ & 1.207 & 0.027 & 1.104 & 0.030 & 1.188 & 0.026 \\
\hline$p_{86}$ & 1.183 & 0.028 & 1.091 & 0.031 & 1.165 & 0.026 \\
\hline$p_{87}$ & 1.162 & 0.029 & 1.061 & 0.031 & 1.140 & 0.027 \\
\hline$p_{88}$ & 1.158 & 0.030 & 1.071 & 0.031 & 1.139 & 0.028 \\
\hline$p_{89}$ & 1.173 & 0.030 & 1.086 & 0.032 & 1.153 & 0.028 \\
\hline$p_{90}$ & 1.162 & 0.029 & 1.098 & 0.031 & 1.151 & 0.028 \\
\hline$p_{91}$ & 1.276 & 0.031 & 1.212 & 0.033 & 1.271 & 0.031 \\
\hline$p_{92}$ & 1.284 & 0.032 & 1.229 & 0.033 & 1.282 & 0.031 \\
\hline \multicolumn{7}{|c|}{ Transitory Component } \\
\hline$\sigma_{24 / 25}^{2}$ & 0.189 & 0.043 & 0.172 & 0.044 & 0.182 & 0.042 \\
\hline$\sigma_{26 / 28}^{2}$ & 0.134 & 0.034 & 0.109 & 0.036 & 0.128 & 0.033 \\
\hline$\sigma_{28 / 29}^{2}$ & 0.164 & 0.037 & 0.125 & 0.039 & 0.160 & 0.037 \\
\hline$\sigma_{30 / 31}^{2}$ & 0.121 & 0.032 & 0.076 & 0.034 & 0.117 & 0.032 \\
\hline$\sigma_{32 / 33}^{2}$ & 0.117 & 0.030 & 0.063 & 0.031 & 0.116 & 0.029 \\
\hline$\sigma_{34 / 35}^{2}$ & 0.186 & 0.043 & 0.136 & 0.042 & 0.179 & 0.041 \\
\hline$\sigma_{36 / 37}^{2}$ & 0.136 & 0.031 & 0.083 & 0.032 & 0.130 & 0.030 \\
\hline$\sigma_{38 / 39}^{2}$ & 0.092 & 0.027 & 0.042 & 0.028 & 0.084 & 0.026 \\
\hline
\end{tabular}

Notes: Source -- Revenue Canada T-4 Supplementary Tax File. 
Table 7 (cont.)

\begin{tabular}{|c|c|c|c|c|c|c|}
\hline & \multicolumn{2}{|c|}{ Restricted Model 1} & \multicolumn{2}{|c|}{ Restricted Model 2} & \multicolumn{2}{|c|}{ Restricted Model 3} \\
\hline & Estimate & $\begin{array}{c}\text { Standard } \\
\text { Error }\end{array}$ & Estimate & $\begin{array}{c}\text { Standard } \\
\text { Error }\end{array}$ & Estimate & $\begin{array}{c}\text { Standard } \\
\text { Error }\end{array}$ \\
\hline$\overline{\sigma_{40 / 41}^{2}}$ & 0.117 & 0.027 & 0.072 & 0.028 & 0.105 & 0.027 \\
\hline$\sigma_{42 / 43}^{2}$ & 0.125 & 0.025 & 0.088 & 0.026 & 0.108 & 0.025 \\
\hline$\sigma_{44 / 45}^{2}$ & 0.105 & 0.030 & 0.077 & 0.031 & 0.082 & 0.029 \\
\hline$\sigma_{46 / 47}^{2}$ & 0.111 & 0.021 & 0.088 & 0.021 & 0.084 & 0.022 \\
\hline$\sigma_{48 / 49}^{2}$ & 0.121 & 0.023 & 0.106 & 0.022 & 0.089 & 0.023 \\
\hline$\sigma_{50 / 51}^{2}$ & 0.196 & 0.023 & 0.195 & 0.022 & 0.154 & 0.025 \\
\hline$\sigma_{52 / 53}^{2}$ & 0.183 & 0.025 & 0.190 & 0.023 & 0.144 & 0.025 \\
\hline$\sigma_{54 / 55}^{2}$ & 0.272 & 0.027 & 0.190 & 0.023 & 0.237 & 0.027 \\
\hline$\sigma_{56 / 57}^{2}$ & 0.329 & 0.028 & 0.292 & 0.026 & 0.288 & 0.028 \\
\hline$\sigma_{58 / 59}^{2}$ & 0.394 & 0.027 & 0.360 & 0.026 & 0.351 & 0.028 \\
\hline$\sigma_{60 / 61}^{2}$ & 0.409 & 0.025 & 0.413 & 0.025 & 0.366 & 0.026 \\
\hline$\rho$ & 0.676 & 0.009 & 0.717 & 0.011 & 0.637 & 0.010 \\
\hline$\gamma_{0}$ & 0.093 & 0.009 & 0.046 & 0.005 & 0.068 & 0.004 \\
\hline$\gamma_{1}$ & -0.004 & 0.002 & & & & \\
\hline$\gamma_{2}$ & -0.00002 & 0.00012 & & & & \\
\hline$\gamma_{3}$ & $3.31 \mathrm{E}-06$ & $2.67 \mathrm{E}-06$ & & & & \\
\hline$\gamma_{4}$ & $8.80 \mathrm{E}-09$ & $1.81 \mathrm{E}-08$ & & & & \\
\hline$\lambda_{n}$ & 1.000 & & 1.000 & & 1.000 & \\
\hline$\lambda_{78}$ & 1.075 & 0.045 & 1.096 & 0.056 & 1.077 & 0.040 \\
\hline$\lambda_{79}$ & 0.894 & 0.037 & 0.943 & 0.047 & 0.909 & 0.033 \\
\hline$\lambda_{80}$ & 0.987 & 0.044 & 1.035 & 0.057 & 0.987 & 0.039 \\
\hline$\lambda_{81}$ & 0.966 & 0.045 & 1.028 & 0.057 & 0.938 & 0.037 \\
\hline$\lambda_{82}$ & 1.261 & 0.060 & 1.291 & 0.070 & 1.164 & 0.044 \\
\hline$\lambda_{83}$ & 1.324 & 0.059 & 1.405 & 0.073 & 1.233 & 0.045 \\
\hline$\lambda_{84}$ & 1.167 & 0.057 & 1.188 & 0.064 & 1.098 & 0.043 \\
\hline$\lambda_{85}$ & 1.159 & 0.055 & 1.207 & 0.066 & 1.066 & 0.043 \\
\hline$\lambda_{86}$ & 1.189 & 0.056 & 1.208 & 0.065 & 1.109 & 0.043 \\
\hline$\lambda_{87}$ & 1.168 & 0.056 & 1.234 & 0.070 & 1.111 & 0.047 \\
\hline$\lambda_{88}$ & 1.190 & 0.054 & 1.209 & 0.065 & 1.116 & 0.044 \\
\hline$\lambda_{89}$ & 1.199 & 0.056 & 1.207 & 0.069 & 1.110 & 0.048 \\
\hline$\lambda_{90}$ & 1.327 & 0.057 & 1.299 & 0.068 & 1.199 & 0.046 \\
\hline$\lambda_{91}$ & 1.428 & 0.063 & 1.395 & 0.075 & 1.262 & 0.051 \\
\hline$\lambda_{92}$ & 1.612 & 0.071 & 1.655 & 0.086 & 1.448 & 0.053 \\
\hline
\end{tabular}


Table 8: Wald Tests of Model Restrictions.

\begin{tabular}{lcccc}
\hline Model & Restriction & $\chi^{2}$ & $\begin{array}{c}\text { Degrees of } \\
\text { Freedom }\end{array}$ & P-value \\
\hline Base Model & $\sigma_{24 / 25}^{2}=\sigma_{26 / 27}^{2}=\ldots=\sigma_{60 / 61}^{2}$ & 380.584 & 18 & 0.0000 \\
& $\gamma_{1}=0, \gamma_{2}=0, \gamma_{3}=0, \gamma_{4}=0$ & 94.630 & 4 & 0.0000 \\
& $\sigma_{\beta}^{2}=0, \sigma_{\alpha \beta}=0$ & 54.661 & 2 & 0.0000 \\
Extended & $\sigma_{\psi}^{2}=0, \sigma_{\alpha \psi}=0, \sigma_{\beta \psi}=0$ & 6.189 & 3 & 0.1028 \\
Model 1 & $\sigma_{\alpha(24 / 25)}^{2}=\sigma_{\alpha(26 / 27)}^{2}=\ldots=\sigma_{\alpha(60 / 61)}^{2}$ & 114.557 & 18 & 0.0000 \\
Extended & $\sigma_{\psi}^{2}=0, \sigma_{\alpha \psi}=0, \sigma_{\beta \psi}=0$ & 24.046 & 3 & 0.0000 \\
Model 2 &
\end{tabular}

Notes: Source -- Revenue Canada T-4 Supplementary Tax File. 
Table 9: The Variance of Years of Education by Cohort

\begin{tabular}{lcccc}
\hline Census & 1976 & 1981 & 1986 & $\sigma_{\alpha}^{2}$ \\
\hline Cohort & & & & \\
\hline $1924 / 25$ & 18.784 & 19.510 & & 0.266 \\
$1926 / 27$ & 16.909 & 18.353 & & 0.245 \\
$1928 / 29$ & 17.606 & 17.690 & 18.413 & 0.227 \\
$1930 / 31$ & 17.682 & 18.182 & 18.131 & 0.203 \\
$1932 / 33$ & 17.598 & 17.464 & 18.267 & 0.171 \\
$1934 / 35$ & 18.327 & 17.581 & 17.447 & 0.201 \\
$1936 / 37$ & 18.122 & 17.884 & 17.322 & 0.177 \\
$1938 / 39$ & 17.539 & 17.057 & 17.564 & 0.157 \\
$1940 / 41$ & 17.198 & 17.057 & 17.032 & 0.147 \\
$1942 / 43$ & 15.571 & 16.966 & 16.322 & 0.142 \\
$1944 / 45$ & 15.832 & 15.904 & 15.351 & 0.137 \\
$1946 / 47$ & 13.638 & 15.171 & 13.506 & 0.121 \\
$1948 / 49$ & 12.881 & 13.786 & 12.709 & 0.110 \\
$1950 / 51$ & 11.290 & 13.061 & 11.553 & 0.113 \\
$1952 / 53$ & & 11.567 & 10.699 & 0.108 \\
$1954 / 55$ & & 9.960 & 9.622 & 0.107 \\
$1956 / 57$ & & 8.970 & 9.000 & 0.104 \\
$1958 / 59$ & & & 8.538 & 0.101 \\
$1960 / 61$ & & & 8.214 & 0.106 \\
\hline Correlation & 0.821 & 0.834 & 0.850 & \\
with $\sigma_{\alpha}^{2}$ & & & & \\
\hline
\end{tabular}

Notes: Source -- 1976, 1981 and 1986 Canadian censuses. Sample -- men who worked in the reference week. Cohort specific estimates of $\sigma_{\alpha}^{2}$ are from extended model 2 in Table 5. 


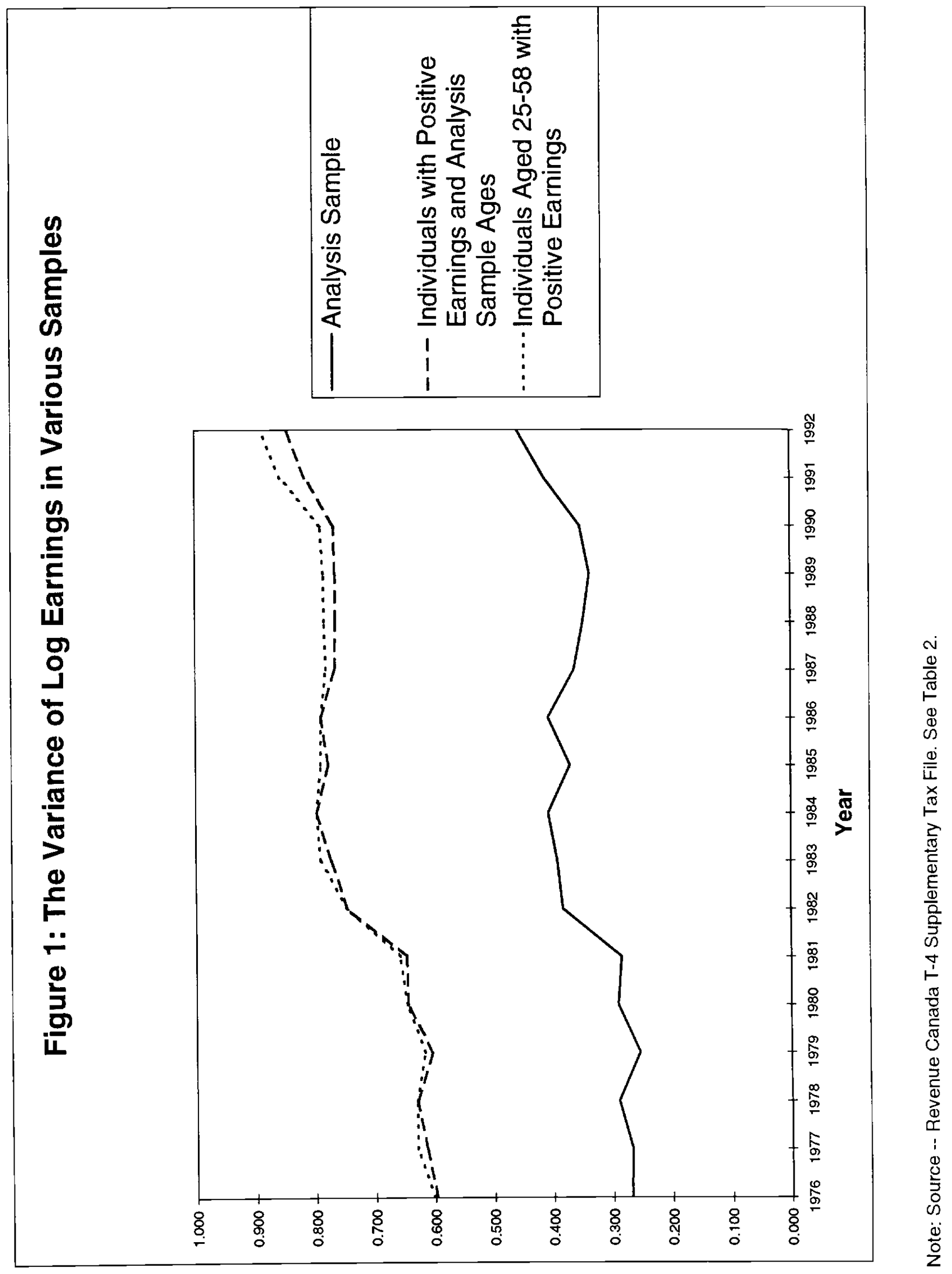




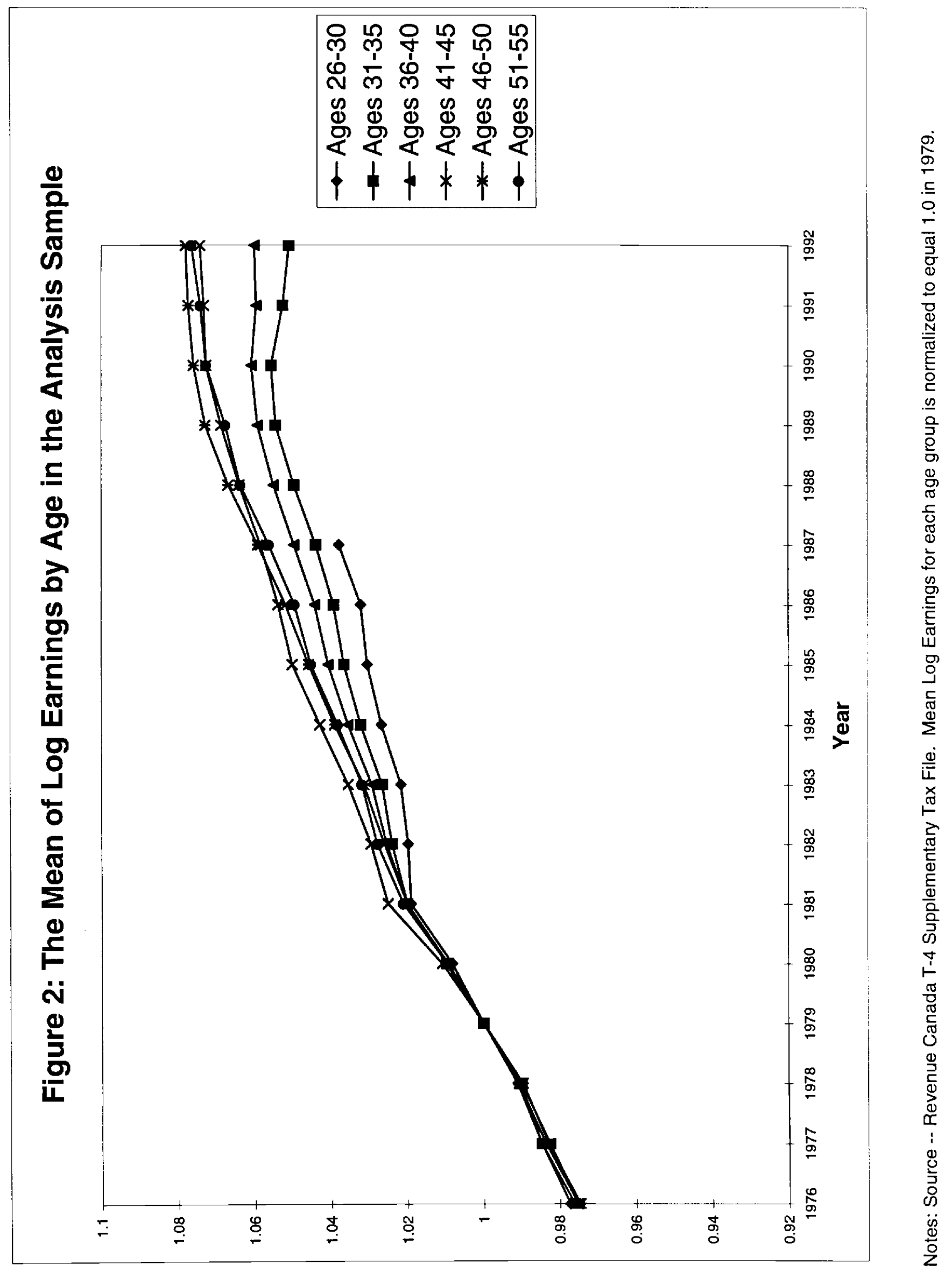




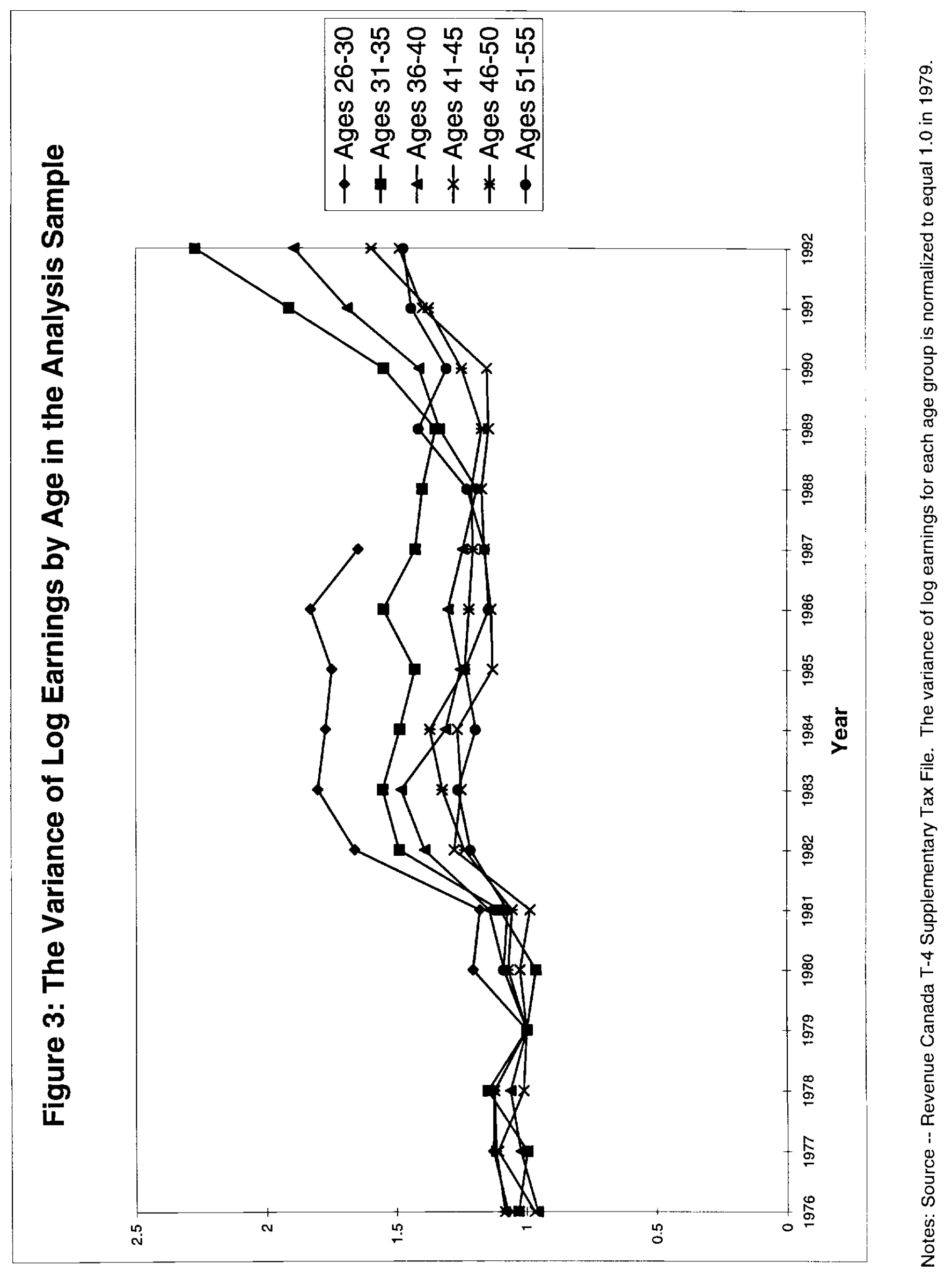




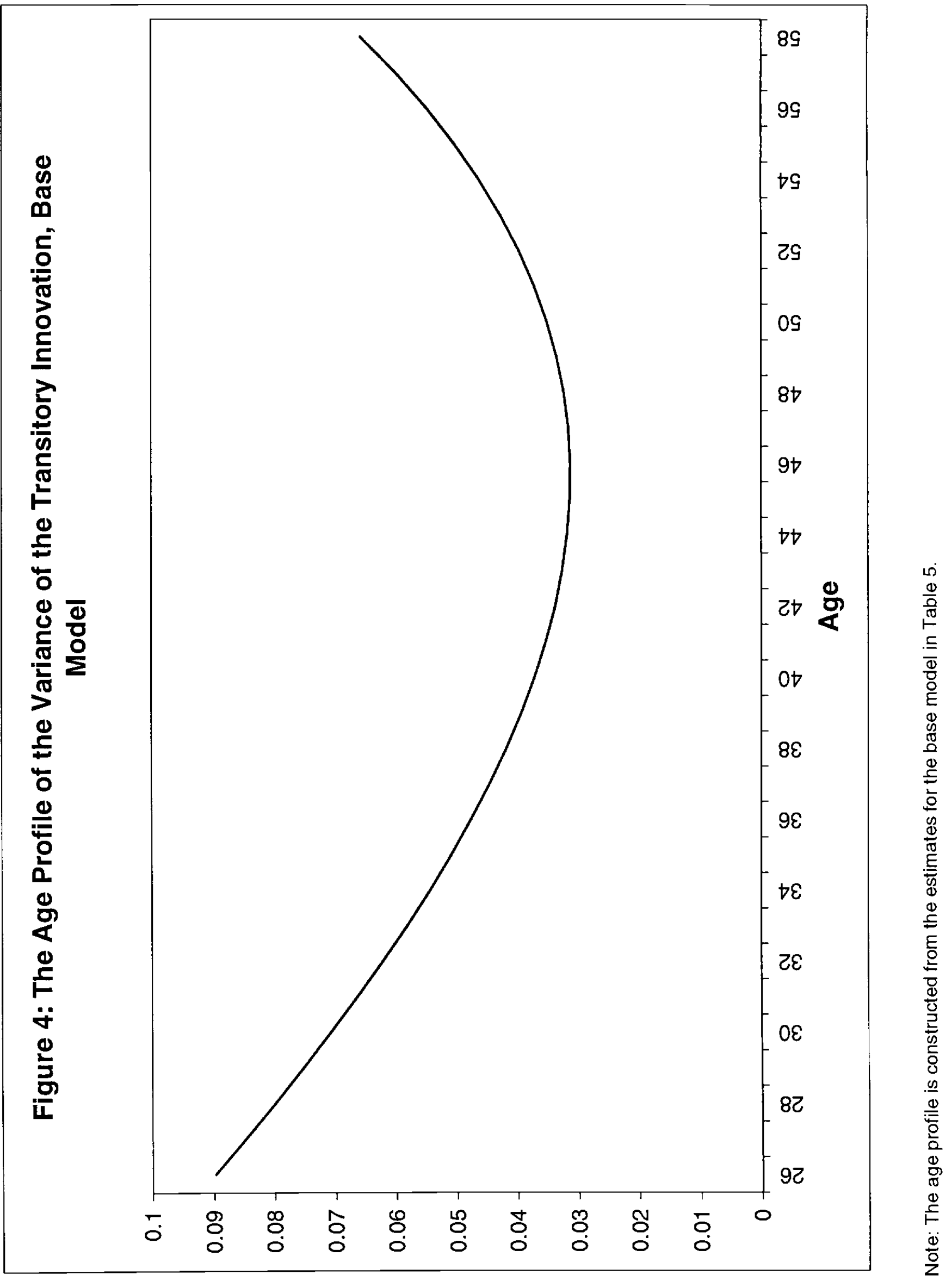




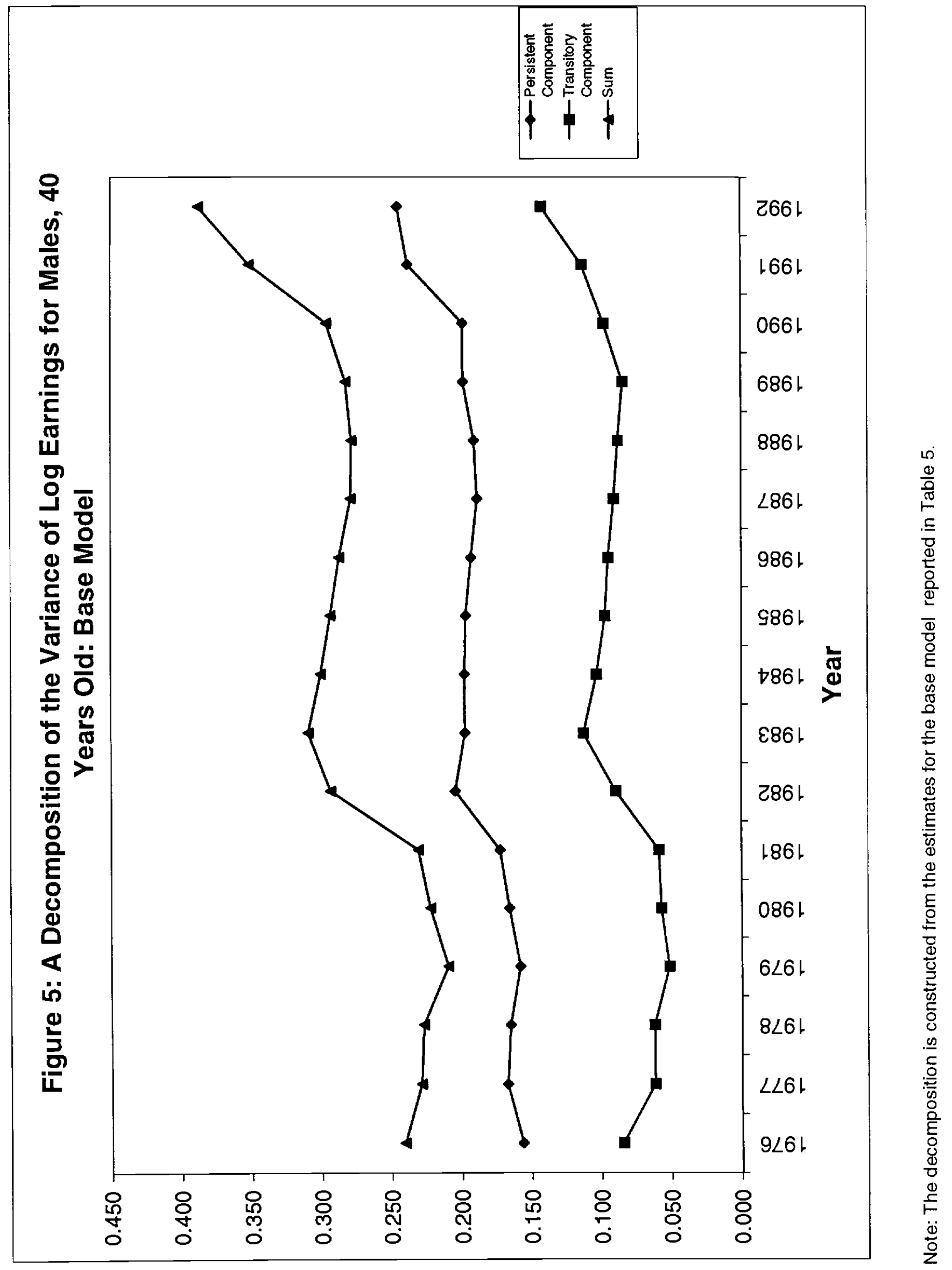




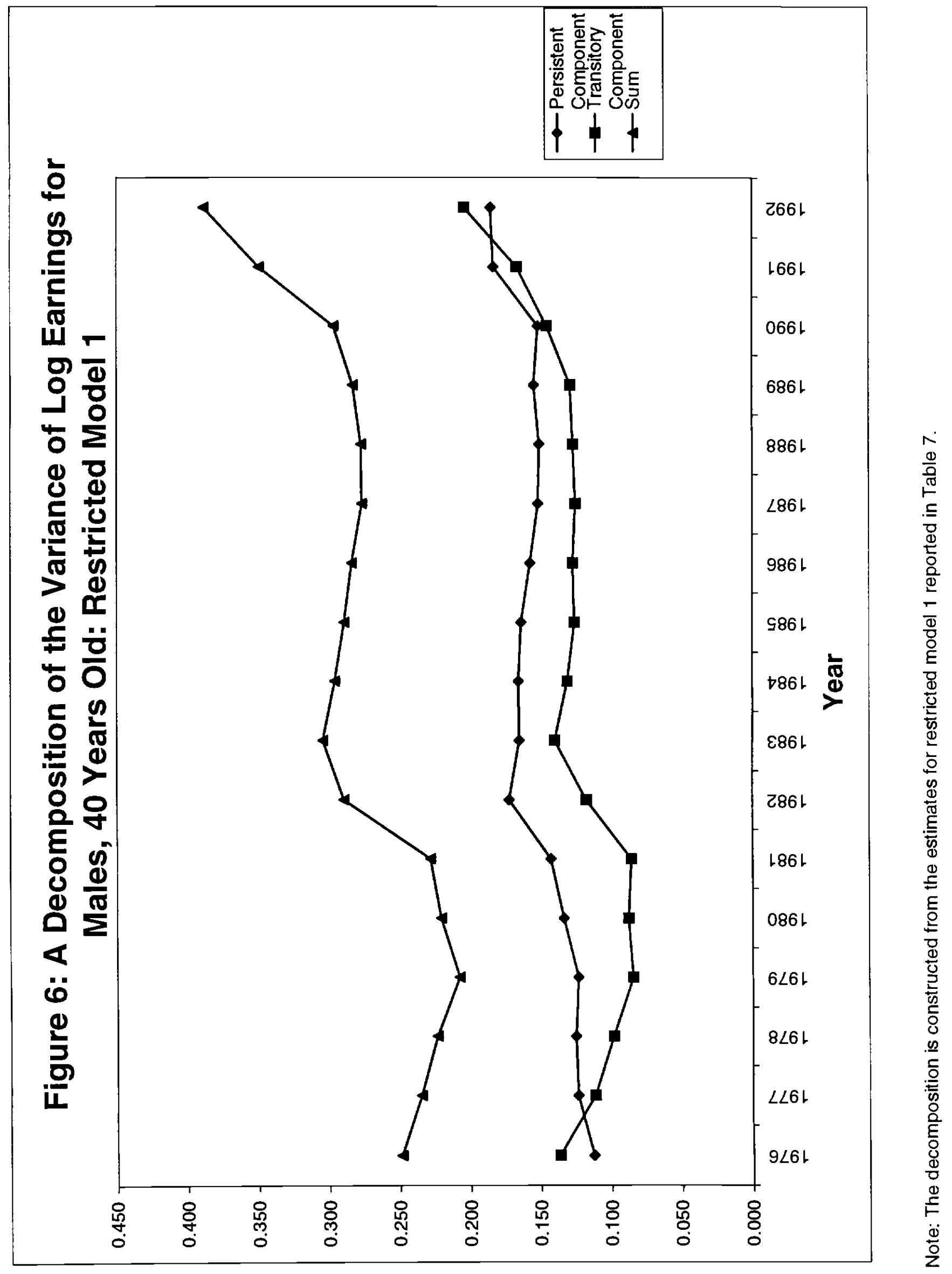




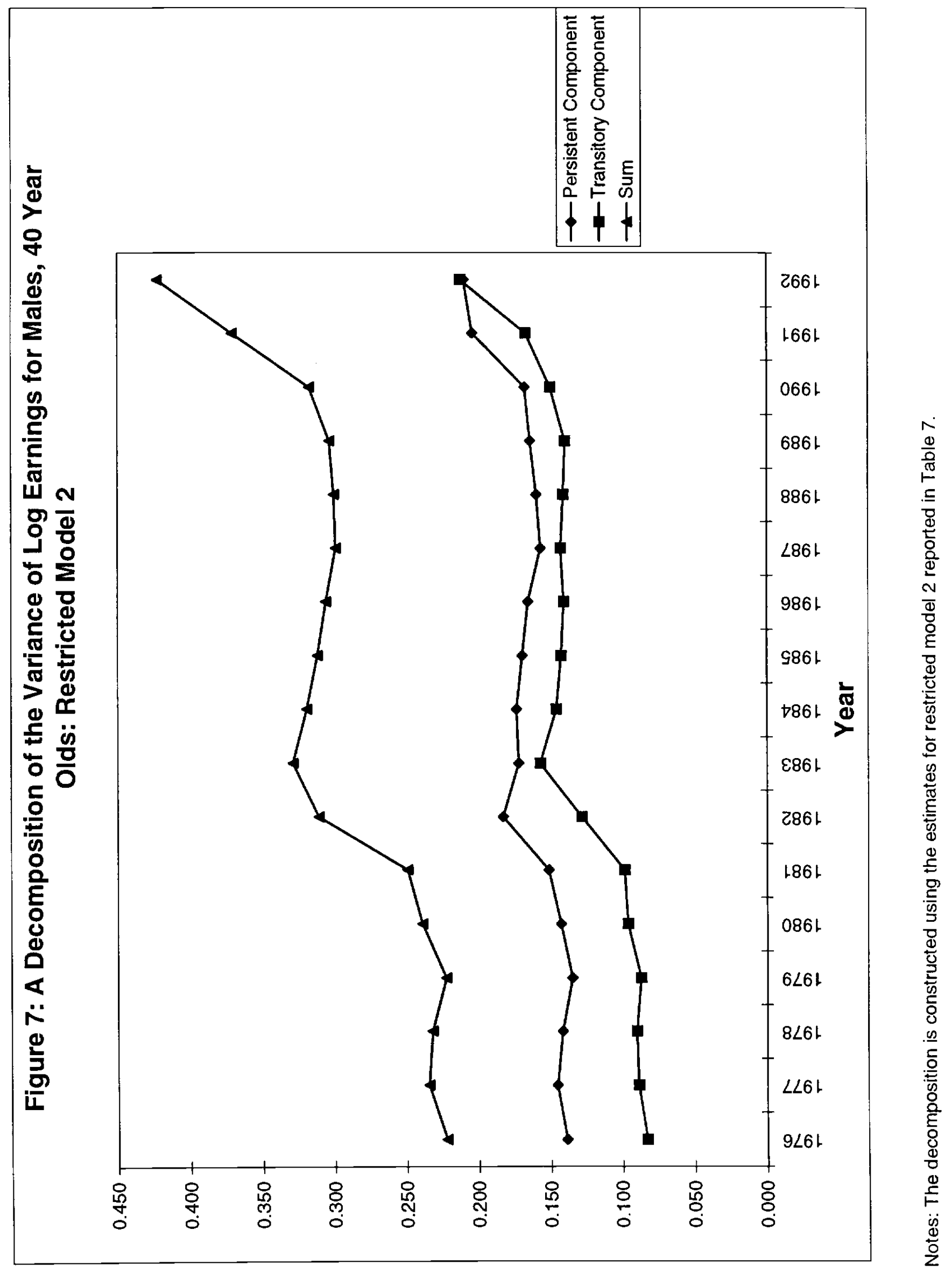




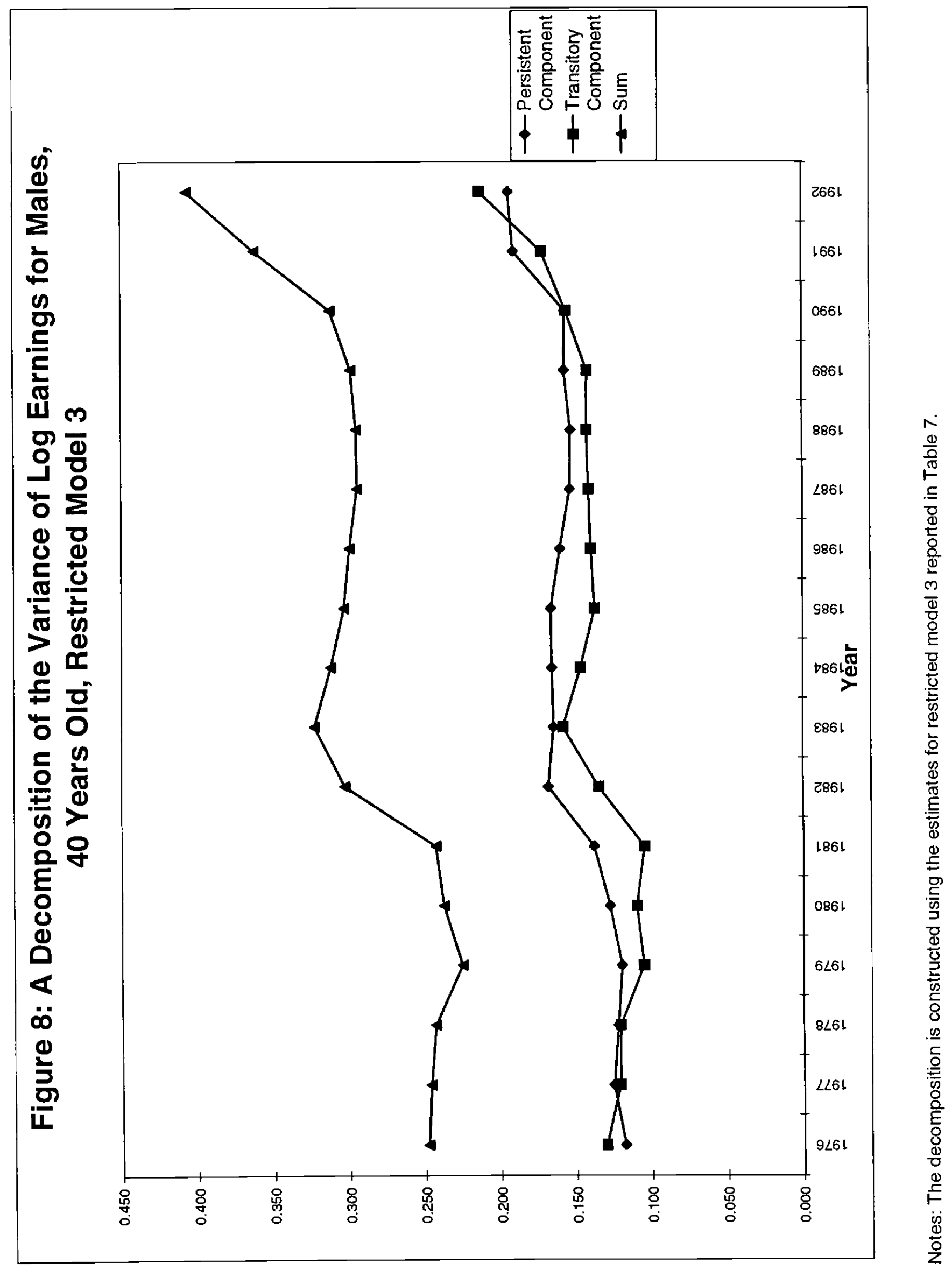




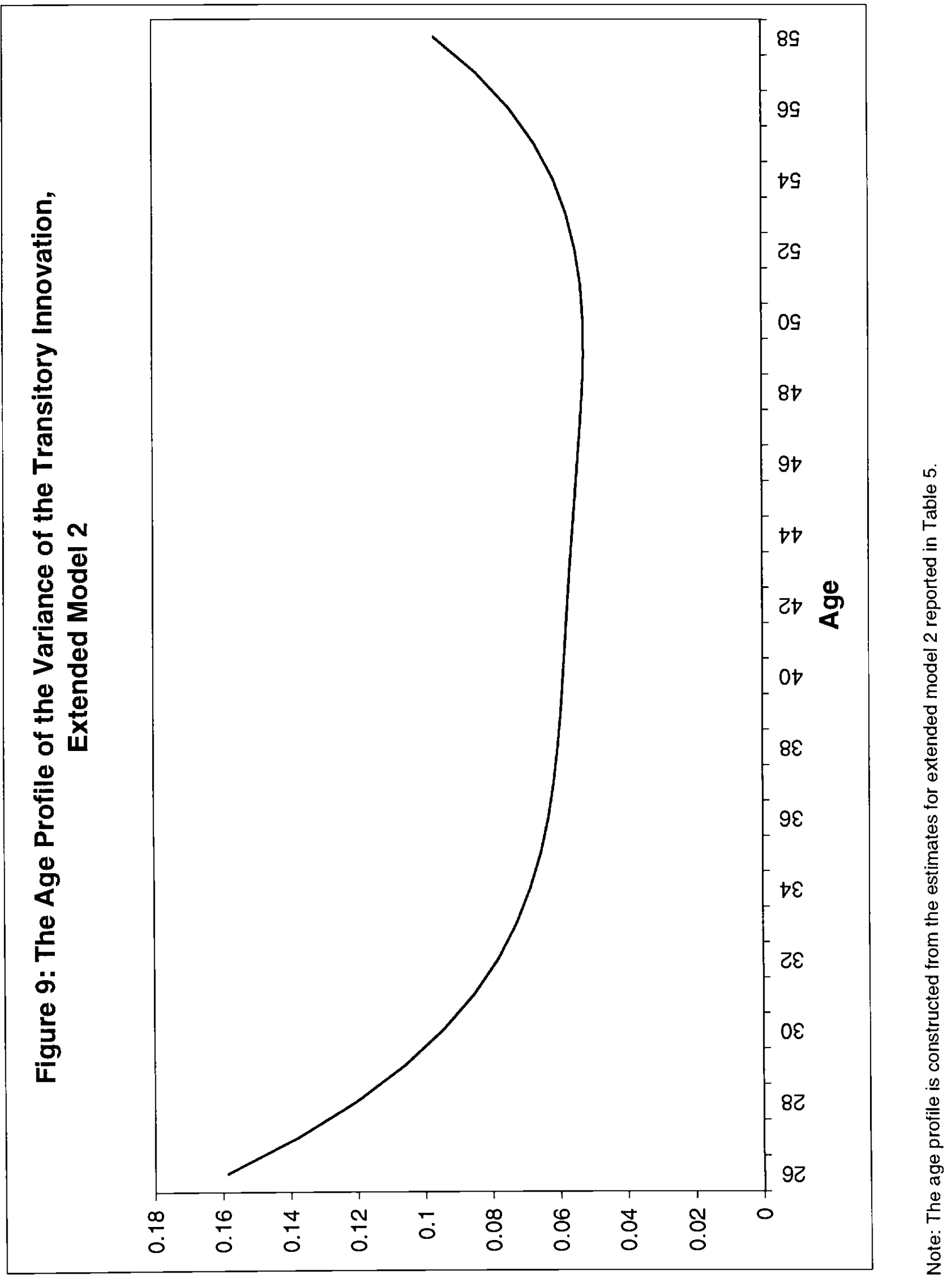




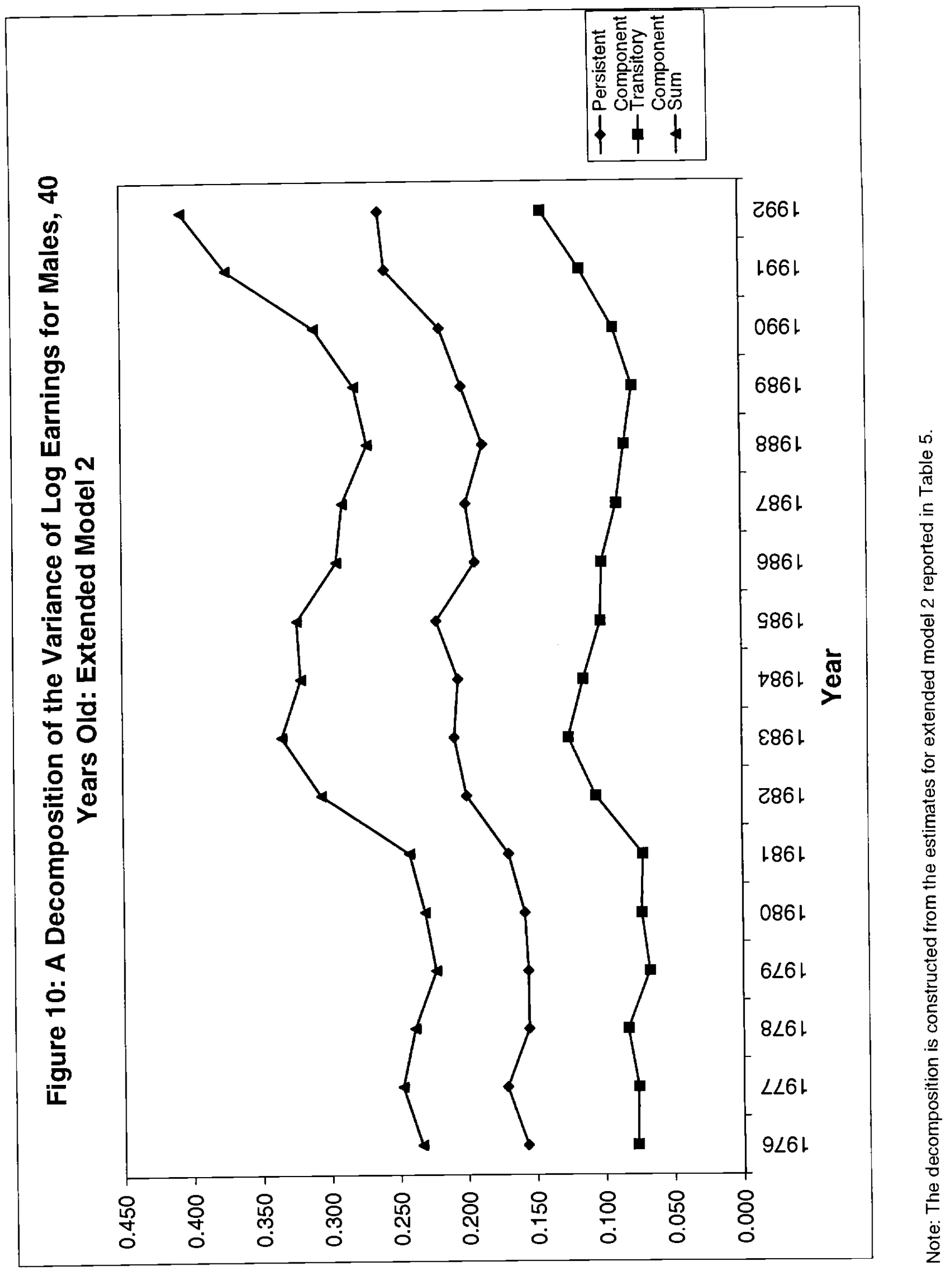

